\title{
La argumentación persuasiva en primaria desde la secuencia didáctica con enfoque metacognitivo ${ }^{1}$
}

\author{
Lina María Moreno Serna (1) \\ Angelmiro Galindo (D) \\ Andrés Felipe Murillo (1) \\ Universidad del Quindío \\ Armenia, Colombia
}

\section{Resumen}

Esta investigación cualitativa, con diseño de investigación-acción, evaluó el impacto de la implementación de una secuencia didáctica con enfoque metacognitivo sobre la construcción de la organización discursiva y el uso de mecanismos persuasivos en la producción argumentativa persuasiva de carácter electoral, escrita en español/LM. La muestra poblacional, seleccionada por el método no probabilístico, estuvo compuesta por estudiantes en 5. ${ }^{\circ}$ grado de primaria de inmersión en inglés/L2 en una institución educativa pública de un municipio del Quindío, Colombia. Participaron 37 estudiantes en la prueba diagnóstica y 27 en la prueba final. Cuatro fases constituyeron el diseño de investigación: diagnóstico, planificación, acción y evaluación. Los instrumentos de recolección de datos fueron: (1) Prueba de escritura en español/LM del texto argumentativo persuasivo de carácter electoral, (2) Rúbrica de evaluación de dicha prueba, (3) Entrevista de reflexión del estudiante sobre el proceso de escritura y habilidades metacognitivas, (4) Portafolio del estudiante y (5) Entrevista de reflexión del docente sobre estrategias de enseñanza metacognitivas y percepción de la escritura argumentativa persuasiva. Los resultados de la evaluación respectiva indicaron que el impacto en las medidas de organización del discurso argumentativo y en el uso de los mecanismos persuasivos dependió de las medidas de evaluación involucradas. Los resultados del seguimiento mostraron el

\footnotetext{
1 Este artículo es un producto de la investigación Propuesta de una intervención didáctica metacognitiva para el mejoramiento del texto argumentativo escrito en lengua materna en $5^{\circ}$ grado en un contexto educativo público bilingüe del Quindío (Código No. 965), del Grupo de Investigación en Bilingüismo, desarrollada entre agosto de 2019 y diciembre de 2020, con la financiación de la Vicerrectoría de Investigaciones de la Universidad del Quindío, Colombia.
} 
comportamiento metacognitivo en la producción escrita focalizada, así como el uso de la estructura textual y de los mecanismos de persuasión. Se concluyó que la secuencia didáctica implementada mejoró en los estudiantes el dominio de varios mecanismos de la organización textual y de persuasión.

Palabras clave: argumentación persuasiva; organización discursiva; mecanismos persuasivos; secuencia didáctica metacognitiva.

\section{Abstract \\ Persuasive argumentation in elementary school based on a didactic sequence with a metacognitive approach}

This qualitative action-research study evaluated the impact of the implementation of a didactic sequence with a metacognitive approach on the construction of discursive organization and the use of persuasive mechanisms in the persuasive argumentative text of electoral nature, written by the participants of the study in Spanish L1. Participants were a non-probabilistic sample of $375^{\text {th }}$ graders from a bilingual public school (English L2 immersion program) in Quindío, Colombia. Thirty-seven students participated in the diagnostic test and 27 in the final test. Four phases constituted the research design: diagnosis, planning, action and evaluation. The data collection instruments were: (1) Spanish L1 writing test of the electoral persuasive text, (2) Evaluation rubric, (3) Student reflection interview on the writing process and metacognitive skills, (4) Student portfolio, and (5) Teacher reflection interview on metacognitive teaching strategies and perception of persuasive argumentative writing. Results from the assessment of students' writing indicated that the impact on both measures of argumentative discourse organization and use of persuasive mechanisms were related to the assessment measures involved. The results of the observation evidenced the metacognitive behavior in the focused written production, as well as the use of textual structure and persuasive mechanisms. It was concluded that the didactic sequence implemented improved students' mastery of several mechanisms of textual organization and persuasion.

Key words: discursive organization; persuasive argumentation; persuasive mechanisms; metacognitive didactic sequence.

\section{Résumé}

\section{L'argumentation persuasive à l'école primaire à partir de la séquence didactique avec une approche métacognitive}

Cette recherche qualitative, avec une démarche de recherche-action a évalué l'impact de la mise en œuvre d'une séquence didactique avec une approche métacognitive sur la construction de l'organisation discursive et l'utilisation de mécanismes persuasifs dans la production argumentative persuasive de nature électorale, écrite en espagnol/LM. L'échantillon de population, sélectionné par la méthode non probabiliste, était composé d'élèves de CM2 en immersion en anglais/L2 dans un établissement d'enseignement public d'une municipalité de Quindío, Colombie. Trente-sept étudiants ont fait le test de diagnostic et 27 au test final. Le plan de 
recherche comprend quatre phases: le diagnostic, la planification, l'action et l'évaluation. Les instruments de collecte de données ont été : (1) Test d'écriture en espagnol/LM du texte argumentatif persuasif électoral, (2) Rubrique d'évaluation du test mentionné, (3) Entretien de réflexion de l'élève sur le processus d'écriture et les compétences métacognitives, (4) Portfolio de l'élève, et (5) Entretien de réflexion de l'enseignant sur les stratégies d'enseignement métacognitives et la perception de l'écriture argumentative persuasive. Les résultats des évaluations respectives ont indiqué que l'impact sur les mesures de l'organisation du discours argumentatif et de l'utilisation de dispositifs de persuasion dépendait des mesures d'évaluation impliquées. Les résultats de l'observation ont mis en évidence le comportement métacognitif dans la production écrite ciblée, ainsi que l'utilisation de la structure textuelle et des mécanismes de persuasion. En conclusion, la séquence didactique mise en œuvre a amélioré la maitrise de plusieurs mécanismes d'organisation textuelle et de persuasion chez les élèves.

Mots-clés : argumentation persuasive ; mécanismes de persuasion ; organisation du discours ; séquence didactique métacognitive. 


\section{SOBRE LOS AUTORES}

\section{Lina María Moreno Serna}

Magíster en Didáctica del inglés de la Universidad de Caldas (2009) y Magíster en Didáctica de las lenguas, énfasis Socio-didáctica, lenguaje y contactos culturales, de la Universidad Jean Monnet, Saint Étienne, Francia (2018). Estudiante de doctorado en Ciencias de la Educación de la Universidad de Aviñón, Francia. Su línea de investigación es el lenguaje argumentativo en estudiantes en formación bilingüe universitaria de licenciatura en lenguas modernas o afines.

Correo electrónico: 1mmoreno@uniquindio.edu.co

\section{Angelmiro Galindo}

Doctor en Lingüística, énfasis en Bilingüismo y educación bilingüe, de la Universidad Laval, Quebec, Canadá (2002). Su línea de investigación es el bilingüismo escolar en contextos lingüísticamente mayoritarios.

Correo electrónico: agalindo@uniquindio.edu.co

\section{Andrés Felipe Murillo}

Magíster en Educación bilingüe de la Universidad Internacional de la Rioja, España (2017). Ha participado en proyectos de formación docente. Sus líneas de investigación son: (1) La didáctica del bilingüismo, (2) Bilingüismo desde la psicolingüística y (3) Competencias bilingües.

Correo electrónico: afmurillo@uniquindio.edu.co

\section{CÓMO CITAR ESTE ARTÍCULO}

Moreno, L., Galindo, A., \& Murillo, A. (2021). La argumentación persuasiva en primaria desde la secuencia didáctica con enfoque metacognitivo. Lenguaje, 49(2), 438-483. https://doi.org/10.25100/lenguaje.v49i2.11019. 


\section{INTRODUCCIÓN}

En investigación educativa, ciencias de la educación, del lenguaje, cognitivas y en la sociedad digital, el desarrollo de competencias argumentativas escriturales es un tema de actualidad. En el ámbito educativo, la argumentación escrita es esencial en el desarrollo de competencias de pensamiento crítico y propositivo, necesarias para la evaluación crítica y presentación de propuestas en la solución de problemas del entorno (Guzmán-Cedillo y Flores, 2020). En efecto, aprender a argumentar constituye un contenido fundamental para la formación de ciudadanos capaces de opinar, participar y construir una sociedad democrática y plural (Camps y Dolz, 1995). Se reconoce, igualmente, que la destreza en la competencia argumentativa no solamente es espontánea, sino que también es aprendida en interacciones sociales, en las que para participar se necesita de una visión crítica sobre la postura de los interlocutores, además de articular adecuadamente un lenguaje con los conocimientos que fundamentan los argumentos propios (Giménez et al., 2014). El estudio aquí reportado giró en torno a la producción de la tipología textual argumentativa escrita en español/LM de estudiantes colombianos de 5..$^{\circ}$ grado de primaria, beneficiarios de un programa de educación bilingüe, siendo la condición de educación bilingüe parte del contexto de la investigación y no una variable que determine dicha producción textual.

En el contexto educativo colombiano, el Ministerio de Educación Nacional [MEN] (2017), por medio de los Derechos Básicos de Aprendizaje (DBA), estableció los aprendizajes que los estudiantes deben desarrollar en los grados escolares de grado 1..$^{\circ}$ a 11. ${ }^{\circ}$ en las áreas del saber: lenguaje, matemáticas, ciencias sociales y ciencias naturales. En particular, en 5. o grado de primaria, grado escolar objetivo de la investigación en reporte, las actividades escolares de los estudiantes incluyen la escritura del texto de carácter argumentativo. Según los DBA (MEN, 2017), desde el área de Lenguaje para dicho grado, en lo concerniente a la argumentación escrita, el estudiante debe: participar en espacios de discusión en los que adapta sus emisiones a los requerimientos de la situación comunicativa, producir textos atendiendo a elementos como el tipo de público al que va dirigido, el contexto de circulación, sus saberes previos y la diversidad de formatos de la que dispone para su presentación; identificar la intención comunicativa de los textos con los que interactúa a partir del análisis de su contenido y estructura, asumir una postura crítica y respetuosa frente a los mensajes que circulan en su medio y, por último, producir textos verbales y no verbales a partir de los planes textuales que elabora según la tipología que va a desarrollar.

En el marco de las políticas educativas para la enseñanza del español en primaria, emitidas por el MEN, entre ellas, los Lineamientos Curriculares de Lengua Castellana (MEN, 1998) y los Estándares Básicos de Competencias en Lenguaje (MEN, 2006), los estudiantes en 5. ${ }^{\text {o }}$ grado de primaria argumentan para el logro de distintos propósitos, entre estos: declarar, convencer y persuadir. Entre los géneros argumentativos, en concordancia con el MEN, que se integran en la formación de 
habilidades en argumentación escrita, se encuentran las cartas de reclamación, los textos publicitarios, las reseñas y las propuestas para el gobierno estudiantil o electorales.

En el contexto colombiano, investigaciones antecedentes en cuanto al dominio de la argumentación escrita de estudiantes de 5. ${ }^{\circ}$ grado de primaria en contexto de educación bilingüe, contexto de la investigación de la que aquí se informa, encontraron carencias relativas al nivel de organización macroestructural del texto y al dominio de mecanismos de organización discursiva argumentativa escrita en LM y en L2. Galindo (2002) halló que estudiantes hispanohablantes de 5. grado de primaria por inmersión precoz parcial en inglés necesitarían mejorar el desarrollo de argumentos pertinentes según la tesis defendida en español/LM. Igualmente, en este país, Benítez (2011) halló que las dificultades en escritura en inglés/L2 de estudiantes de 5. o grado de primaria por inmersión precoz parcial en inglés fueron la presentación de la tesis sin el desarrollo de ideas para el sustento respectivo, debido a la carencia de vocabulario y la enumeración de ideas sin la definición de la tesis. En estos estudios, el examen del desempeño en la argumentación escrita se centró en aspectos organizacionales y discursivos, tales como la estructura del texto y la argumentación dirigida a declarar y convencer, desde el género argumentativo propio de la carta de solicitud argumentativa. Sin embargo, consideramos que faltaría investigación sobre el desempeño de estudiantes en educación bilingüe en otro tipo de género discursivo argumentativo, en el cual se exploren no solo aspectos de orden organizacional, sino también sociopragmáticos, en este caso, la argumentación persuasiva escrita en LM. En la investigación aquí reportada asumimos que, dentro del contexto social, la argumentación persuasiva cobra relevancia al permitirle al sujeto ser gestor de cambio. Ciertamente, el sujeto argumentador, a través del uso de mecanismos de persuasión, tales como el ethos (credibilidad), pathos (emoción) y logos (lógica), dirigidos a mover la emoción y pasiones del interlocutor, logra generar cambios de pensamiento y conducta en pro de intereses particulares y sociales (Perelman, 1977/1997). De acuerdo con Quintero y Peña (2016), el alcance de la tarea argumentativa persuasiva y su impacto a nivel comunicativo está condicionado por el uso de argumentos pertinentes, según elementos de orden pragmático, como: el destinatario, la situación y el contexto de comunicación. Del mismo modo, los autores en referencia plantean que este tipo de texto debe contar con el uso pertinente de una estructura organizacional.

En el contexto internacional, la investigación en torno a la argumentación persuasiva en la infancia se ha centrado en analizar la habilidad persuasiva de tipo egoísta y prosocial, así como su relación con la competencia lingüística y la comprensión de la mente. Según Barajas et al. (2019), el conjunto de estudios internacionales sobre la persuasión en la infancia muestra resultados en las siguientes líneas: (1) Flexibilidad para generar argumentos diversos y ajustados a los contraargumentos del persuadido o variedad de argumentos, (2) Consideración más profunda de los estados mentales del receptor (calidad de los argumentos) y (3) Uso de argumentos más positivos y aceptables. Es importante indicar que las 
investigaciones previas sobre producción persuasiva se enfocaron en situaciones de persuasión prosocial (Slaughter et al., 2013) y de persuasión en beneficio propio (Bartsch y London, 2000). En el caso de la persuasión prosocial se buscó que los niños realizaran una determinada acción para el beneficio del persuadido. El paradigma habitualmente utilizado en la evaluación de este tipo de persuasión consistió en participar en una situación de role-play, así como en la escritura de textos publicitarios y de propuestas en las que el participante desarrolle argumentos persuasivos para lograr que alguien realice una acción determinada (To et al., 2016).

En el contexto nacional, en el marco de la Constitución Política de Colombia de 1991 y del artículo 142 de la Ley 115 o Ley General de Educación del 08 de febrero de 1994 (Congreso de la República de Colombia, 1994), desde la primaria, se promueven prácticas al interior de las instituciones educativas, que fomentan la democracia, el gobierno estudiantil y el desarrollo de habilidades argumentativas persuasivas. Es en este contexto que cobra vigencia la investigación en la producción argumentativa persuasiva de carácter electoral. Sin embargo, la investigación en torno a dicha temática estaría, según nuestro juicio, en su etapa exploratoria.

Existe la necesidad de examinar el desarrollo y uso por parte de los estudiantes, en particular al finalizar la primaria, de elementos que permiten la elaboración del discurso argumentativo persuasivo de carácter electoral. Entre estos elementos se encuentran los niveles de organización del texto (super, macro y micro) y aquellos de orden socio-pragmático, dirigidos a la interacción con el interlocutor y al cambio de su manera de pensar por medio del uso de mecanismos de persuasión (argumentos de tipo ethos, pathos y logos). Este tipo de discurso goza de circulación social y, por lo demás, se caracteriza por la puesta en escena de mecanismos persuasivos atinentes al ethos, pathos y logos (Perelman, 1977/1997; Perelman y Olbrechts-Tyteca, 1966/1989).

En educación primaria, la argumentación representa una conducta lingüística efectiva de los niños, ligada a procesos de socialización, desarrollo cognitivo y académico (Brassart, 1995; Sánchez y Silva, 2011). Desde una perspectiva general, observamos que, en la escuela, la argumentación no se limita al área de lengua, sino que también se presenta en otras áreas, entre ellas, matemáticas y ciencias naturales y educación ambiental. Es en este sentido que resulta necesario el diseño, implementación y evaluación de herramientas didácticas que fomenten su aprendizaje, como la secuencia didáctica. En el contexto de interés del presente estudio, esto es la educación primaria, se sitúa la implementación de secuencias didácticas desde diversos enfoques de enseñanza como una herramienta para el mejoramiento de aspectos propios de la producción escrita en LM de géneros discursivos argumentativos. Primero, empleo de marcas enunciativas en cartas de solicitud por estudiantes de 3. ${ }^{\circ}$ grado en Argentina, intervenidos con una secuencia didáctica centrada en la organización de la información, el formato, la producción de solicitudes con sus argumentos y la textualización (Sánchez y Silva, 2011). Segundo, escritura de cartas argumentativas con su respectiva estructura por estudiantes de 5. grado en España, expuestos a una secuencia didáctica sociocognitiva (Hidalgo et al., 2019). Finalmente, escritura del ensayo argumentativo con adecuada estructura de la 
secuencia argumentativa por estudiantes mexicanos de 5. grado, expuestos a una intervención didáctica basada en el interaccionismo sociodiscursivo (Rodríguez Hernández et al., 2020).

En el contexto internacional aquí referenciado la implementación de secuencias didácticas para el desarrollo de la argumentación escrita se ha concentrado en enfoques sociocognitivos y discursivos. De acuerdo con la concepción cognoscitiva, el proceso de la escritura involucra el subproceso de la revisión (Hayes y Flower, 1980, 1986). En general, en este subproceso de la escritura, el escritor interviene su propio texto para darle forma y reformularlo, si es necesario. Ahora bien, al concebir el subproceso de revisión como una operación cognitiva clave para la escritura con calidad organizacional y discursiva, hipotetizamos que se fomenta el desarrollo de la metacognición del escritor. En el contexto nacional, en las últimas décadas se observa el impacto del acercamiento metacognitivo y meta-sociocognitivo en la escritura de diferentes tipologías textuales en LM en contexto educativo de primaria. Chaverra (2011) implementó una secuencia didáctica orientada a diagnosticar y desarrollar las habilidades metacognitivas en la escritura de textos digitales en LM de tipo narrativo y argumentativo, entre otros, en estudiantes de 4. ${ }^{\circ}$ y 5. ${ }^{o}$ grado de primaria. Los resultados indicaron que los estudiantes desarrollaron habilidades metacognitivas en lo relacionado con el reconocimiento de la tarea de escritura y de las propias dificultades escriturales. La investigadora en referencia concluyó que los resultados representaban evidencia empírica sobre el carácter enseñable de la metacognición, asociado al desarrollo de la producción textual, y a la competencia del estudiante/escritor sobre la producción de los textos digitales. En esta misma línea investigativa, Quintero y Peña (2016) desarrollaron una investigación-acción en 3. grado de primaria, con el objetivo de implementar la escritura en contexto, fundamentada en la perspectiva sociocultural, el modelo meta sociocognitivo y la noción de cognición situada. Dentro de los hallazgos, estos autores destacaron acciones mediadoras de las docentes investigadoras. Dichas acciones posibilitaron a los estudiantes identificar los procesos de composición escrita, tener una visión global de los momentos a seguir para la culminación del texto escrito, asumir el rol de sujetos escritores y controlar la progresión de sus aprendizajes escriturales.

Fundamentados en los antecedentes investigativos que muestran el alcance de intervenciones centradas en el enfoque metacognitivo, propusimos el diseño y la implementación de una secuencia didáctica con enfoque metacognitivo para mejorar la producción argumentativa persuasiva de carácter electoral, escrita en español/LM, de estudiantes de 5. o grado de primaria beneficiarios de un programa de educación bilingüe. En el sector educativo público de Colombia, en particular en el Quindío, contexto de la investigación en reporte, y en respuesta a los retos de la política pública de bilingüismo nacional y departamental, existen iniciativas de transición del modelo de educación orientado en español/LM al orientado en inglés/L2, con fundamentación pedagógica de la educación por inmersión lingüística (Galindo y Moreno, 2019). Según nuestro conocimiento, en el contexto de tales iniciativas educativas, principalmente en 5. grado de primaria, faltaría investigación sobre la producción 
argumentativa persuasiva de carácter electoral, escrita en LM. En tal sentido, la investigación de la que aquí informamos tuvo como fin evaluar el impacto de la implementación de una secuencia didáctica con enfoque metacognitivo sobre la construcción de la organización discursiva y el uso de mecanismos persuasivos en la producción argumentativa persuasiva de carácter electoral, escrita en español/LM, de estudiantes en 5. o grado de primaria de inmersión en inglés/L2, en una institución educativa pública de un municipio del Quindío, Colombia. Dicha finalidad requirió, primero, diagnosticar tal producción textual $\mathrm{y}$, segundo, diseñar e implementar la secuencia didáctica en referencia.

\section{FUNDAMENTACIÓN TEÓRICA}

Implementar una secuencia didáctica con enfoque metacognitivo para el mejoramiento de la construcción de la organización discursiva y el uso de mecanismos persuasivos en la producción argumentativa persuasiva de carácter electoral, escrita en español/LM, de estudiantes de 5. ․ grado de primaria en educación bilingüe pública de inmersión en inglés/L2 de un municipio del Quindío, Colombia, requirió la siguiente fundamentación teórica. En primer lugar, la condición bilingüe de dicha muestra poblacional correspondió al bilingüismo individual. Propusimos definirlo, en palabras de Galindo y Moreno (2020), como: “Uso que efectúa el bilingüe de sus lenguas-culturas, en una situación de comunicación determinada, con distintos grados de dominio, según sus características individuales y contextuales" (p. 58). Desde el punto de vista educativo, su desarrollo se llevó a cabo en una institución pública de educación bilingüe de enriquecimiento. Un programa educativo de este tipo se dirige a sujetos de LM mayoritaria, para desarrollar en ellos una L2, generalmente, de prestigio internacional (Austin et al., 2015; Baker y Wright, 2017). El modelo pedagógico implementado en dicha institución educativa correspondió al de la educación bilingüe de inmersión temprana y parcial en L2. En dicho modelo, para la enseñanza se utilizan dos lenguas distintas, en proporciones similares de tiempo, desde los primeros grados de la escolaridad: por un lado, el contenido académico disciplinario se enseña en inglés/L2, utilizando la metodología AICLE (Aprendizaje Integrado de Contenidos y Lenguas Extranjeras), y, por el otro, los contenidos no lingüísticos, en español/LM (Galindo y Moreno, 2019; Ovando y Combs, 2018).

En segundo lugar, la producción escrita argumentativa persuasiva de carácter electoral se fundamentó desde el siguiente abordaje teórico. Primero, concebir la argumentación a partir del enfoque teórico de la nueva retórica (Perelman, 1977/1997; Perelman y Olbrechts-Tyteca, 2000). En general, desde este enfoque, la argumentación es inseparable de la comunicación y es, por lo demás, una actividad de uso del lenguaje y del pensamiento encaminada a provocar, mantener o acrecentar la adhesión del interlocutor a la tesis que se le presenta. En este enfoque, Perelman (1977/1997) afirma que la argumentación busca "incitar a la acción, o, por lo menos, crear una disposición a la acción" (p. 32). Segundo, la argumentación persuasiva es un acto perlocucionario, esto es, uno de los efectos producidos por un hablante sobre otro 
mediante un discurso (Austin, 1962) e, igualmente, está orientada a un auditorio particular (Perelman y Olbrechts-Tyteca, 1966/1989). Consideramos, entonces, que la argumentación persuasiva, eje rector del texto argumentativo persuasivo de carácter electoral, sería "una actividad discursiva con una función pragmática específica: conducir, por medio de la presentación de uno o varios argumentos, a un auditorio particular a adherirse a una determinada tesis electoral o a potenciar su adhesión". Tercero, en el enfoque teórico de la nueva retórica, desarrollado por Perelman y Olbrechts-Tyteca (1966/1989) y Perelman (1977/1997), un texto argumentativo persuasivo es eficaz cuando logra llevar al receptor a adherirse a la postura defendida por el sujeto argumentador. Cuarto, durante el proceso de la persuasión, el sujeto argumentador pone en escena mecanismos persuasivos, que le permiten seleccionar argumentos por ethos, pathos y logos (Fernández y López, 2020). Para estos autores, dicha tipología de argumentos se define como sigue: el ethos, de orden afectivo, configura la imagen de credibilidad del sujeto argumentador, apela a su autoridad y honestidad. El pathos, de orden afectivo, está ligado al receptor del discurso. El logos apunta directamente a la razón, está ligado al tema y al mensaje mismo del discurso. Postulamos que, a través de estos tipos de argumentos, la tesis expuesta adquiere fuerza persuasiva electoral, lo que impulsaría al auditorio a la acción, es decir, a votar a su favor. En efecto, todo acto persuasivo está caracterizado por la unión de elementos propios de la razón (logos) y otros de la pasión (ethos y pathos), ya que "el objetivo del discurso es hacer creer algo al otro, de manera que este último esté en posición de deber creer" (Charaudeau, 2009, p. 281). Finalmente, la argumentación persuasiva en política, desde un enfoque pragmático de la comunicación, presenta una tesis, sustentada con argumentos provenientes de la razón (logos) y de los sentimientos (pathos y ethos) con el fin, por un lado, de lograr la respectiva adhesión del auditorio y, por el otro, de captar su voto de apoyo (Cardete et al., 2019).

En tercer lugar, hicimos el acercamiento a la organización discursiva del texto argumentativo persuasivo de carácter electoral, según el modelo de análisis textual de Kintsch y Van Dijk (1978) y Van Dijk (1978/1992, 2005). Tal organización se presenta en tres niveles: (a) Superestructura: esquema estructural básico del texto, independiente de su contenido, (b) Macroestructura: organización coherente del contenido semántico del texto a nivel global y (c) Microestructura: compuesta por elementos locales y superficiales que hacen que un texto sea cohesivo y coherente, es decir, la relación coherente entre oraciones sucesivas del texto. Según los autores en referencia, estos niveles estructurales se convierten en guía para que el lector pueda inferir los significados a través del discurso desarrollado. Igualmente, estos tres niveles de la organización textual se concretan en el texto argumentativo persuasivo de carácter electoral, según los teóricos en referencia, de la siguiente manera: para producir la macroestructura y microestructura del texto, el sujeto argumentador se orienta mediante la superestructura, esto es, guiarse por un esquema formal cognoscitivo, que regule la elaboración de la macro y microestructura.

La noción de secuencia didáctica con enfoque metacognitivo es el último pilar de la fundamentación teórica de la presente investigación. Señalamos un acercamiento 
teórico al concepto de secuencia didáctica desde la perspectiva didáctica, en particular, la desarrollada por Díaz Barriga (2013). Para este autor, la secuencia didáctica comprende una línea de actividades sucesivas (apertura, desarrollo y cierre) y planeadas por el docente para enseñar un contenido educativo particular. En tal sentido, proponemos, en el documento en curso, caracterizar la secuencia didáctica metacognitiva así: línea de actividades sucesivas (apertura, desarrollo y cierre), modeladas por el docente. Postulamos que, de su implementación, se espera que el alumno mejore en la construcción de la organización discursiva y en el uso de mecanismos persuasivos que componen su texto argumentativo persuasivo de carácter electoral, escrito en español/LM, motivándolo al conocimiento y regulación de sus procesos de pensamiento implicados en el desarrollo de tal actividad de escritura. Por su parte, la metacognición, en psicología cognitiva, se refiere al control de los propios procesos de pensamiento para construir conocimiento (Flavell, 1976). En el ámbito de la educación y de la psicología del aprendizaje, desde una perspectiva general, se plantea que la metacognición es un camino para aprender a aprender y que permite la formación de estudiantes autónomos. Desde estos referentes teóricos, consideramos que, en una secuencia didáctica con enfoque metacognitivo, el docente crea el ambiente de aprendizaje para permitir al estudiante el uso de diversos recursos para planificar, controlar y evaluar el aprendizaje de los mecanismos que aseguran la organización discursiva y persuasiva de la tipología textual en referencia. Adicionalmente, emplea actividades centradas en estrategias de enseñanza metacognitivas, como el modelamiento cognitivo y metacognitivo, la interrogación metacognitiva y la discusión metacognitiva (Johnson y Johnson, 1975). Asimismo, dicha secuencia didáctica podría, según los autores del presente artículo, convertirse en guía para el docente, con el fin de generar actividades de aprendizaje dirigidas a consolidar en los estudiantes el dominio de las fases de la tarea de escritura: planificación textual, producción o redacción y revisión.

\section{Metodología}

Los participantes y el contexto fueron: primero, grupo de intervención integrado por estudiantes hispanohablantes colombianos, de edad promedio de 10.4 años. Su grado de escolaridad correspondió al 5. de primaria de educación bilingüe pública de enriquecimiento por inmersión temprana y parcial en inglés/L2 en un municipio del Quindío, Colombia. Segundo, 37 estudiantes participaron en la prueba diagnóstica y 27 en la prueba final. La emergencia sanitaria por la COVID-19, durante la implementación de la secuencia didáctica metacognitiva, causó dicha deserción. Tercero, participación voluntaria de los estudiantes, previa formalización del asentimiento y del consentimiento informado (Paz Maldonado, 2018) e, igualmente, seleccionados por el método no probabilístico (Hernández-Sampieri y Mendoza Torres, 2018). 
La investigación aquí reportada fue un estudio cualitativo de investigaciónacción (Efron y Ravid, 2020; Elliot, 2000). Su espiral de ciclos de cuatro fases se desarrolló en 20 semanas:

- Fase 1: Diagnóstico de la situación (Dos semanas). Identificación de las necesidades de mejoramiento en la producción argumentativa persuasiva de carácter electoral, escrita en español/LM, a partir de la aplicación de la prueba de escritura en español/LM del texto argumentativo persuasivo de carácter electoral, diseñada según la argumentación persuasiva (Perelman, 1977/1997; Perelman y Olbrechts-Tyteca, 1966/1989). El respectivo estímulo de escritura fue: escribir en español/LM una propuesta de campaña electoral para ser elegido como representante del 5. ${ }^{\circ}$ grado al Consejo Estudiantil de la Institución Educativa. Su validación incluyó: (1) Cálculo del índice de validez de contenido (IVC) de 1, mediante el juicio independiente de cinco expertos, utilizando el modelo de Lawshe (1975), y (2) Cálculo del índice de dificultad del $70 \%$, en un grupo piloto. La prueba respectiva en el Anexo A.

La rúbrica de evaluación de la producción escrita recolectada, diseñada por los investigadores, constó de dos secciones: (1) Niveles de la organización discursiva: superestructura, macroestructura y microestructura y Mecanismos de persuasión del ethos, pathos y logos. La superestructura se verificó a través de cuatro medidas de evaluación: (1) Naturaleza argumentativa persuasiva electoral, (2) Planteamiento de la tesis, (3) Argumentos desarrollados en sustento de la tesis y (4) Enunciación de la conclusión. La primera fue de orden funcional superior de carácter eliminatorio: si el texto evaluado carecía de dicha naturaleza, se le excluía de la evaluación. La valoración de dichas variables se realizó mediante una distribución asociada a ensayos de Bernoulli; esto es, cada variable tomó solo dos valores: 1 con probabilidad $p$ (aciertos) y 0 con probabilidad $q$ (desaciertos). La macroestructura se valoró según siete medidas de evaluación: (1) Función socio-pragmática persuasiva electoral, (2) Función persuasiva de la tesis, (3) Relación lógica entre argumentos y función socio-pragmática persuasiva electoral, (4) Relación lógica entre argumentos y función persuasiva de la tesis, (5) Coherencia entre argumentos desarrollados, (6) Relación de la conclusión con la Función socio-pragmática persuasiva electoral y (7) Relación de la conclusión con la tesis persuasiva. La microestructura se evaluó mediante cuatro medidas de evaluación: (1) Mecanismos de unión de las ideas: función argumentativa de los marcadores textuales, (2) Mecanismos de cohesión léxica: repetición, la reiteración y la asociación, (3) Relaciones entre las ideas por medio de los signos de puntuación y (4) Relación lógica entre las palabras que conforman una frase: concordancia gramatical. Los mecanismos persuasivos focalizados se evaluaron como sigue: identificación del número de argumentos a través del texto y valoración de su fuerza persuasiva. La valoración de los niveles macroestructurales, microestructurales y de la fuerza persuasiva del 
ethos, pathos y logos se hizo en una escala Likert de cinco opciones de respuesta: 1=Deficiente, 2=Insuficiente, 3= Aceptable, 4= Suficiente y 5= Excelente. Validamos la rúbrica de evaluación en referencia mediante el cálculo del IVC, basado en el juicio de cinco expertos (IVC $=1$ ). Dos evaluadores colombianos, independientes y externos, evaluaron la prueba diagnóstica, con un acuerdo interjueces de 1 calculado mediante el índice kappa. Antes del proceso respectivo de evaluación, fueron entrenados en un estudio piloto. Son graduados de un programa de licenciatura en el área de Humanidades y Lengua Castellana y, por lo demás, poseen experiencia profesional en la enseñanza del español en primaria.

- Fase 2: Planificación (Dos semanas). Formulación del plan de acción para mejorar la situación diagnosticada, articulada en dos acciones. Primera, diseño de la secuencia didáctica metacognitiva, sobre los siguientes principios: (1) Estrategias de enseñanza metacognitivas (modelamiento cognitivo y metacognitivo, interrogación metacognitiva y discusión metacognitiva), de Johnson y Johnson (1975), (2) Habilidades metacognitivas de los estudiantes (conocimiento metacognitivo y desarrollo de la regulación metacognitiva), según Veenman (2016) y Winne y Azevedo (2014), (3) Construcción de la organización discursiva en tres niveles: superestructura, macroestructura y microestructura (Kintsch y Van Dijk, 1978; Van Dijk, 1978/1992, 2005) y (4) Mecanismos de persuasión del ethos, pathos y logos (Fernández y López, 2020). La segunda acción fue la línea de implementación, en tres actividades (apertura, desarrollo y cierre), de la secuencia didáctica diseñada (Díaz Barriga, 2013) tal y como se ilustra en la Tabla 1.

Tabla 1. Línea de actividades en la implementación de la secuencia didáctica

\begin{tabular}{|c|c|c|c|c|c|}
\hline \multirow{2}{*}{$\begin{array}{l}\text { Actividades de } \\
\text { la Secuencia } \\
\text { didáctica }\end{array}$} & Apertura & \multicolumn{3}{|c|}{ Desarrollo } & Cierre \\
\hline & \multicolumn{5}{|c|}{$\begin{array}{c}\text { Estrategias de enseñanza metacognitivas } \\
\text { Modelamiento cognitivo y metacognitivo, interrogación metacognitiva y discusión } \\
\text { metacognitiva, adaptado de Johnson y Johnson (1975) }\end{array}$} \\
\hline $\begin{array}{l}\text { Unidades de } \\
\text { trabajo }\end{array}$ & Unidad 1 & Unidad 2 & Unidad 3 & Unidad 4 & Unidad 5 \\
\hline $\begin{array}{l}\text { Objetivos de } \\
\text { los talleres en } \\
\text { las unidades } \\
\text { de trabajo }\end{array}$ & $\begin{array}{l}\text { Analizar la } \\
\text { función del } \\
\text { texto } \\
\text { argumentativo }\end{array}$ & $\begin{array}{l}\text { Analizar y } \\
\text { proponer la } \\
\text { super y } \\
\text { macroestruct } \\
\text { ura del texto } \\
\text { argumentati } \\
\text { vo }\end{array}$ & $\begin{array}{l}\text { Identificar la } \\
\text { finalidad y } \\
\text { alcance de los } \\
\text { textos } \\
\text { persuasivos } \\
\text { electorales }\end{array}$ & $\begin{array}{l}\text { Elaborar la } \\
\text { micro estructura } \\
\text { del texto } \\
\text { argumentativo y } \\
\text { argumentos } \\
\text { persuasivos } \\
\text { electorales } \\
\text { desde los } \\
\text { mecanismos de } \\
\text { persuasión }\end{array}$ & $\begin{array}{l}\text { - Construir la } \\
\text { propuesta } \\
\text { electoral } \\
\text { o Autoevaluar } \\
\text { el desempeño } \\
\text { en la } \\
\text { propuesta } \\
\text { electoral }\end{array}$ \\
\hline
\end{tabular}

Fuente: elaboración propia 
Durante las tres actividades se diseñaron cinco unidades de trabajo, cada una con su respectivo taller. El objetivo de la línea de implementación propuesta fue permitir al estudiante progresar desde el aprestamiento y sensibilización en cuanto a la argumentación hasta la elaboración de la propuesta electoral.

- Fase 3: Acción (14 semanas). Puesta en práctica del plan formulado y seguimiento de su impacto en el contexto respectivo. La implementación de la línea de actividades correspondiente a la secuencia didáctica y las unidades estuvo asistida desde la interacción, práctica y retroalimentación por las herramientas virtuales WhatsApp y la plataforma educativa Integratic (Suárez Lantarón, 2018). La secuencia didáctica desde la fase 2 fue diseñada con el objetivo de ser implementada en el aula de clase bajo la metodología presencial. Sin embargo, al momento de ejecutar la fase 3 se presentó la emergencia sanitaria generada por la COVID-19. Consecuentemente, con el objetivo de dar una respuesta estratégica y proactiva al reto impuesto por dicha emergencia sanitaria, esto es, las condiciones de confinamiento y educación a distancia y remota, se adoptó la metodología de la enseñanza mediada por la virtualidad a través de sesiones sincrónicas y asincrónicas. Mediante la plataforma educativa Integratic, se realizaron las sesiones asincrónicas. Dicha plataforma facilita a los estudiantes el acceso a la información, es decir, a contendidos académicos sin necesidad de estar conectados a internet. Los estudiantes tienen la posibilidad de acceder a tareas, archivos, chat, foros y grupos de trabajo en línea donde pueden discutir dudas y ayudarse mutuamente en el momento en que lo requieran. Los docentes, por su parte, estructuran su espacio de enseñanza al subir material pedagógico y organizar contenidos. Del mismo modo, los docentes tienen la posibilidad de compartir y encontrar recursos digitales entre toda la comunidad educativa. En cuanto a los padres de familia, estos pueden solicitar las notas académicas, colocar justificantes, pedir permisos y faltas, hablar con los profesionales y personal administrativo siempre que tengan una duda o pregunta y participar de foros de padres. Para lograr la integración de dicha plataforma en el proceso de enseñanza aprendizaje, desde el grado primero, los estudiantes y padres de familia son instruidos en su uso por parte de los docentes directores de grupo. Durante la implementación, el docente publicó y compartió los contenidos del curso y las unidades de trabajo cada 15 días. Continuamente el docente brindó retroalimentación escrita sobre el desarrollo de los talleres por medio del foro y chat. En cuanto a la herramienta WhatsApp, esta permitió el desarrollo de las unidades de la secuencia didáctica mediante la instrucción sincrónica guiada. Durante las sesiones de clase sincrónicas, que tenían una duración de hora y media, dos veces por semana, para un total de 28 sesiones el docente explicaba el objetivo, las actividades de desarrollo y evaluativas que se encontraban en la plataforma Integratic. Asimismo, mantenía interacción constante para clarificar y dar seguimiento a la comprensión y aplicación de las actividades de orden metacognitivo. 
Tres categorías preestablecidas principales, cada una con sus subcategorías, guiaron la implementación y el seguimiento de la secuencia didáctica con enfoque metacognitivo, tal y como se ilustra en la Tabla 2.

Tabla 2. Categorías y subcategorías para la implementación y seguimiento de la secuencia didáctica con enfoque metacognitivo

\begin{tabular}{|c|c|}
\hline \multicolumn{2}{|c|}{$\begin{array}{l}\text { Enfoque metacognitivo centrado en estrategias de enseñanza metacognitivas: } \\
\text { modelamiento cognitivo y metacognitivo, interrogación metacognitiva y discusión } \\
\text { metacognitiva, adaptado de Johnson y Johnson (1975) }\end{array}$} \\
\hline Categorías principales & Subcategorías \\
\hline $\begin{array}{l}\text { 1. Comportamiento metacognitivo en la } \\
\text { producción escrita en español/LM del texto } \\
\text { argumentativo persuasivo de carácter } \\
\text { electoral, atinente a las habilidades } \\
\text { metacognitivas y proceso de escritura } \\
\text { (Veenman, 2016; Winne y Azevedo, 2014) }\end{array}$ & $\begin{array}{l}\text { 1. Autoevaluación y reflexión sobre los } \\
\text { procesos comunicativos } \\
\text { 2. Activación de conocimientos previos } \\
\text { 3. Resolución de un problema } \\
\text { 4. Ordenamiento y secuenciación } \\
\text { 5. Proceso metacognitivo de escritura } \\
\text { (planeación, textualización y revisión) } \\
\text { 6. Análisis y uso metapragmático de los } \\
\text { mecanismos de persuasión }\end{array}$ \\
\hline $\begin{array}{l}\text { 2. Desempeño en la construcción de la estructura } \\
\text { textual (Kintsch y Van Dijk, 1978; Van Dijk, } \\
\text { 1978/1992, 2005) }\end{array}$ & $\begin{array}{l}\text { 1. Superestructura } \\
\text { 2. Macroestructura } \\
\text { 3. Microestructura }\end{array}$ \\
\hline $\begin{array}{l}\text { 3. Desempeño en el uso de mecanismos de } \\
\text { persuasión (Fernández y López, 2020). }\end{array}$ & $\begin{array}{l}\text { 1. Ethos } \\
\text { 2. Pathos } \\
\text { 3. Logos }\end{array}$ \\
\hline
\end{tabular}

Fuente: elaboración propia

La secuencia didáctica con enfoque metacognitivo consistió en el uso de actividades de la siguiente naturaleza al interior de los talleres: (1) Modelamiento cognitivo y metacognitivo, (2) Interrogación metacognitiva, (3) Discusión metacognitiva. En cada taller, se inició con actividades de modelamiento cognitivo y se culminó con las correspondientes a la discusión metacognitiva. Dentro de las actividades anteriormente mencionadas los ejercicios de enseñanza de orden metacognitivo correspondieron a las siguientes subcategorías de la categoría principal No. 1 (Comportamiento metacognitivo en la producción escrita en español/LM de una propuesta electoral con enfoque argumentativo persuasivo): (a) Autoevaluación y reflexión sobre los procesos comunicativos, (b) Activación de conocimientos previos, (c) Resolución de un problema, (d) Ordenamiento y secuenciación, (e) Proceso metacognitivo de escritura (planeación, textualización y revisión) y (f) Análisis y uso metapragmático de los mecanismos de persuasión). Específicamente, el comportamiento metacognitivo en la producción escrita en español/LM de una propuesta electoral con enfoque argumentativo persuasivo se observó según la manera como el estudiante empleó los ejercicios anteriormente mencionados en el aprendizaje y la elaboración de los textos. De acuerdo con Hayes y Flower (1980), la integración de dicho tipo de ejercicios en la enseñanza de la escritura favorece el 
desarrollo de la escritura como proceso. Dichos ejercicios no solo constituyeron la estrategia de enseñanza, sino que también representaron la naturaleza del tipo de estrategias metacognitivas empleadas por el estudiante. Las categorías principales No. 1 y No. 2 permitieron darle seguimiento al uso de los niveles de la organización discursiva y a los mecanismos de persuasión.

Tres instrumentos de recolección de datos permitieron el seguimiento de la implementación: Primero, Entrevista de reflexión del estudiante sobre el proceso de escritura y habilidades metacognitivas. Suministró información acerca la primera categoría principal y subcategorías establecidas. Esto es permitió indagar sobre lo sucedido en la mente del escritor antes, durante y después del acto de escritura e identificar su conocimiento desarrollado sobre su propia actividad cognitiva, su capacidad de ejecución de la tarea de escritura solicitada y la regulación de las estrategias para el logro de dicha tarea (Veenman, 2016; Winne y Azevedo, 2014). Esta entrevista contó con 10 preguntas, que apuntaron a obtener información sobre las siguientes categorías: (a) autoevaluación y reflexión sobre los procesos comunicativos, (b) análisis y uso metapragmático de los mecanismos de persuasión y (c) proceso metacognitivo de escritura (planeación, textualización y revisión). Esta entrevista fue llevada a cabo por dos investigadores del proyecto a través de llamadas grupales de WhatsApp. La respectiva entrevista figura en el Anexo B.

Segundo, Portafolio del estudiante. Posibilitó evaluar su proceso de aprendizaje, agrupar sus trabajos académicos y recolectar sus reflexiones de orden metacognitivo (Esteves et al., 2020). Específicamente, desde el portafolio se indagó acerca de las tres categorías principales. En el portafolio se incluyeron cinco talleres desarrollados por los estudiantes. Dichos talleres fueron entregados por parte del docente del curso a los estudiantes de manera física. Una vez desarrollados por los estudiantes, fueron cargados a la plataforma educativa Integratic. Los estudiantes con problemas de conectividad o que no contaban con computador enviaron los talleres vía WhatsApp o los entregaron de manera física al colegio para su posterior revisión. Una vez la docente recibía el taller en la plataforma o de manera física, el docente empleó una matriz en la cual registraba por cada estudiante la identificación de las categorías y subcategorías según el desempeño del estudiante en el taller de cada unidad.

Tercero, Entrevista de reflexión del docente sobre estrategias de enseñanza metacognitivas y percepción de la escritura argumentativa persuasiva. Proporcionó información sobre las estrategias implementadas por el docente antes de la investigación y sobre sus impresiones frente al alcance de las estrategias metacognitivas implementadas durante la investigación (O'Leary, 2017). Esta entrevista fue llevada a cabo por dos investigadores del proyecto a través de una video llamada utilizando el software de video chat Zoom. La entrevista tuvo como objetivo principal conocer la percepción del docente del curso en cuanto al desarrollo y alcance de la implementación en el proceso de enseñanza aprendizaje del texto argumentativo persuasivo de carácter electoral. Esta entrevista contó con 10 preguntas que apuntaron a obtener información sobre las siguientes categorías: (a) estrategias metacognitivas 
de enseñanza, (b) percepción de la argumentación persuasiva de carácter electoral, (c) autoevaluación y reflexión sobre los procesos comunicativos (d) desempeño en la construcción de la estructura textual, (e) análisis y uso metapragmático de los mecanismos de persuasión y (f) proceso metacognitivo de escritura (planeación, textualización y revisión). La respectiva entrevista figura en el Anexo C.

Las entrevistas en referencia, diseñadas por los investigadores, se validaron mediante el cálculo del IVC, basado en el juicio de cinco expertos (IVC=1). Los respectivos audios y grabaciones fueron transcritos literalmente, en un primer texto, mediante la herramienta online de reconocimiento de voz Amberscript. Este texto fue posteriormente normalizado, según los protocolos de la transcripción ortográfica para los corpus lingüísticos del Instituto Caro y Cuervo de Bogotá, Colombia (Bejarano et al., 2018).

- Fase 4: Evaluación de la acción (Dos semanas). Evaluación del impacto de la secuencia didáctica implementada en la situación educativa diagnosticada, tomando como fuentes de insumo el seguimiento a la implementación y las pruebas de diagnóstico y la prueba final. Dos evaluadores colombianos, independientes y externos, evaluaron la prueba final, con un acuerdo interjueces de 1 calculado mediante el índice kappa.

\section{Resultados}

Esta investigación de corte cualitativo y con diseño de investigación-acción evaluó el impacto de la implementación de una secuencia didáctica con enfoque metacognitivo sobre la construcción de la organización discursiva y el uso de mecanismos persuasivos en la producción argumentativa persuasiva de carácter electoral, escrita en español/LM, de estudiantes de 5. grado de primaria de inmersión en inglés/L2 en una institución educativa pública de un municipio del Quindío, Colombia. La construcción de la organización discursiva tuvo que ver con los niveles de la estructura argumentativa relativos a la superestructura, macroestructura y microestructura. El uso de mecanismos persuasivos concernió el desarrollo de argumentos ethos, pathos y logos. Presentamos los resultados respectivos teniendo en cuenta el ciclo de la investigación-acción, según sus fases de diagnóstico, seguimiento y evaluación.

\section{Diagnóstico de Niveles de la Organización Discursiva y Mecanismos de Persuasión}

Participaron 37 estudiantes en la prueba diagnóstica. En primer lugar, los resultados el diagnóstico de las cuatro medidas de evaluación de la superestructura, clasificadas como variables cualitativas nominales dicotómicas, en una escala nominal, fueron: primero, la proporción del parámetro $p$ (éxito) en la medida de evaluación de carácter eliminatorio (Naturaleza argumentativa persuasiva electoral) equivalió al $84 \%$, es decir, 31 casos de 37 observados. Segundo, en esta misma proporción se identificaron argumentos desarrollados en sustento de la tesis de la propuesta electoral. Dicho 
diagnóstico reveló, igualmente, proporciones del parámetro $q$ (fracaso). En concreto, de los 31 estudiantes que escribieron una propuesta electoral con enfoque argumentativo persuasivo, 14 (38\%) plantearon la tesis y 12 (32\%) enunciaron la conclusión respectiva. Segundo, el diagnóstico desglosado del nivel macroestructural fue: (1) Desempeño Deficiente en cuatro medidas de evaluación, de siete focalizadas: función persuasiva de la tesis, relación lógica entre argumentos y función sociopragmática persuasiva electoral, relación de la conclusión con la función sociopragmática persuasiva electoral y relación de la conclusión con la tesis persuasiva, (2) Desempeño Aceptable en tres medidas de evaluación de las siete focalizadas: función socio-pragmática persuasiva electoral, relación lógica entre argumentos y función socio-pragmática persuasiva electoral y coherencia entre argumentos desarrollados. La mediana del diagnóstico global respectivo fue de 2 , es decir, desempeño Insuficiente. Tercero, el diagnóstico desglosado del nivel microestructural fue: (1) Desempeño Aceptable en tres medidas de evaluación de las cuatro focalizadas: mecanismos de unión de las ideas: función argumentativa de los marcadores textuales, mecanismos de cohesión léxica: repetición, la reiteración y la asociación y relación lógica entre las palabras que conforman una frase: concordancia gramatical y (2) Desempeño Insuficiente en la medida Relaciones entre las ideas por medio de los signos de puntuación. La mediana del diagnóstico global fue de 3, esto es, Aceptable. Por último, el diagnóstico de los mecanismos persuasivos fue: mediana de 3, (desempeño Aceptable) en los argumentos ethos y pathos y mediana de 1 (desempeño Deficiente) en los argumentos logos.

De los resultados del anterior diagnóstico, podríamos resumir que la muestra poblacional diagnosticada tendría que realizar esfuerzos de aprendizaje para mejorar la construcción de la organización discursiva de la propuesta electoral con enfoque argumentativo persuasivo, escrita en español/LM, en el planteamiento de la tesis y la enunciación de la conclusión (superestructura), en las siete medidas de la macroestructura y en las cuatro medidas de la microestructura. Igualmente, debe focalizar esfuerzos de mejoras en los mecanismos persuasivos focalizados de dicha propuesta electoral.

\section{Seguimiento de la Implementación de la Secuencia Didáctica Metacognitiva}

El seguimiento de la implementación respectiva se logró mediante el análisis de contenido (Piñuel, 2002), la categorización deductiva e inductiva de los datos (Marín et al., 2016) y la triangulación hermenéutica (Cisterna, 2005). Los datos obtenidos se codificaron mediante el software para datos cualitativos ATLAS.ti7, por dos expertos. A continuación, la síntesis de resultados sobre las tres categorías preestablecidas, definidas en la Fase 3 (Acción) de la espiral de ciclos de la investigación-acción aquí reportada. En la primera categoría Comportamiento metacognitivo en la producción escrita en español/LM de una propuesta electoral con enfoque argumentativo persuasivo (Veenman, 2016; Winne y Azevedo, 2014), los resultados de cada una de las subcategorías fueron: 
- Autoevaluación y reflexión sobre los procesos comunicativos. Se observa una conciencia sobre aspectos sociopragmáticos como la importancia del discurso empático. Este tipo de comportamiento metacognitivo sería el resultado de la articulación de estrategias de enseñanza metacognitivas y la puesta en escena de ejercicios metacognitivos para la escritura de la propuesta electoral focalizada, tal como lo revela la siguiente evidencia, tomada de la entrevista al docente:

Mm...Inicialmente se trabajaba por medio de la lectura porque era la única forma / ahora en estos momentos virtuales... que los niños leyeran [///] que leyeran el taller de la unidad primero, que nos enteráramos qué era lo que íbamos a tratar $\uparrow$, qué era lo nuevo que íbamos a conocer $\uparrow$. Se activaba un presaber por medio de la lectura de conceptos introductorios. Por medio del WhatsApp se daban todas las instrucciones de cada ejercicio. Con las estrategias metacognitivas, se brindó más autonomía al niño [...] por medio de ejercicios metacognitivos como: los de secuenciación $\rightarrow$, ordenamiento, identificación, corrección y justificación de errores, esquematización del texto por medio de organizadores gráficos, reflexión sobre el proceso de escritura ...y demás ejercicios que llevaron al niño a concentrarse en el proceso de escritura.

- Activación de conocimientos previos. Los estudiantes identificaron situaciones que propiciaron la argumentación y en las cuales ejercieron el rol de sujetos argumentadores, como es el caso de dar una opinión.

- Ordenamiento y secuenciación. En la etapa de estructuración del texto, el estudiante identificó la función de cada una de sus partes, organizándolo de manera progresiva y lógica, a partir de ejercicios de clasificación, categorización, ordenamiento y secuenciación. Una muestra de este comportamiento se observa a continuación en la Figura 1. correspondiente al ejercicio de ordenamiento de la Unidad No. 4.

D. Los siguientes textos argumentativos están en desorden. Ordénalos. A cada texto asígnale el número que corresponde, según la función que cumple dentro del texto, por ejemplo, si se trata de la opinión o de argumentos. 1. Opinión o punto de vista, 2. Argumentos, 3. Argumentos, 4. Conclusión: 
a) Los perros

\begin{tabular}{|c|c|}
\hline$a$ & $\begin{array}{l}\text { Se pueden adaptar al espacio donde se van a llevar y se pueden educar } \\
\text { para que ejecuten órdenes de comportamiento. }\end{array}$ \\
\hline$b$ & $\begin{array}{l}\text { Por ello, los perros son una buna opción para ser elegidos como compañeros en la } \\
\text { convivencia }\end{array}$ \\
\hline C & $\begin{array}{l}\text { Ellos por muchos años han sido conocidos como el mejor amigo del hombre, ya que, } \\
\text { desde que inicia la conexión con esta mascota y el dueño, dificilmente puede romperse o } \\
\text { deteriorarse. }\end{array}$ \\
\hline $\bar{d}$ & $\begin{array}{l}\text { Los perros son animales domésticos que pueden convivir sin ningún inconveniente con } \\
\text { los seres humanos. }\end{array}$ \\
\hline
\end{tabular}

Figura 1. Ejercicio de ordenamiento. Unidad $N^{\circ} 4$

- Proceso metacognitivo de escritura (planeación, textualización y revisión). La progresión en la implementación del enfoque metacognitivo permitió observar la transición a prácticas de escritura de la propuesta electoral focalizada, fundamentadas en habilidades metacognitivas de regulación del proceso de escritura (entre otras: selección, comparación, jerarquización, autocuestionamiento, indagación, revisión mediante rúbrica y acondicionamiento del entorno) y en prácticas de escritura en las que la confianza reside en sus competencias como escritores y en las habilidades y estrategias propias del proceso de escritura.

- Análisis y uso metapragmático de los mecanismos de persuasión. Los estudiantes identificaron la finalidad persuasiva de elementos lingüísticos y extralingüísticos y fueron capaces de discernir sobre qué recursos lingüísticos y extralingüísticos utilizar para lograr persuadir a un público determinado. En los siguientes extractos, tomados de la Entrevista sobre el proceso de escritura y habilidades metacognitivas de la Unidad No. 4, se observó cómo el estudiante fue consciente de la función y del alcance de mecanismos de persuasión como el ethos y el pathos. La convención ENC representa el encuestador y INF el estudiante.

ENC: Pregunta 9: ¿Qué debemos tener en cuenta al momento de escribir un texto persuasivo electoral?

INF 16: Para ello, [/] tengo que dar ideas buenas que atraigan la atención de los demás, luego las defiendo con argumentos y razones, les presento todos los beneficios que pueden obtener si siguen mi idea ...trato de mover los sentimientos de las personas con palabras bonitas $\mathrm{y} \rightarrow$ si es necesario...según el caso... ( ) abrazos y besos. Debo escoger el momento indicado en el que esa persona me pueda prestar atención, de forma calmada y hablando correctamente para que me entienda.

ENC: Pregunta10: ¿Qué cree qué debemos tener en cuenta al momento de votar?

INF 17: Mm...Haber escuchado todas o en su mayoría las propuestas de gobierno de los candidatos. Sus argumentos, curso [--] pues estas llenan favorablemente mis expectativas, para lo que yo deseo que haga por mi pueblo, ciudad, departamento o país. Escuchar...[/] cuando habla en los sitios públicos y $\rightarrow$ cómo es su trato con las demás personas. 
En la segunda categoría (Desempeño en la construcción de la estructura textual), los resultados, según los tres niveles focalizados de la organización discursiva, fueron:

- Superestructura. Adopción de un enfoque inductivo con sentido para estructurar los textos, a partir de ejercicios de modelamiento cognitivo y metacognitivo, que explicaban la naturaleza y función de los distintos componentes del texto argumentativo persuasivo electoral (título, tesis, argumentos, conclusión) y del esquema de dicho tipo de texto.

- Macroestructura. Desarrollo de tesis con sentido completo, argumentos que sustentan la tesis en desarrollo y conclusiones coherentes con los argumentos y tesis expuestos. En el siguiente texto, tomado del portafolio, Unidad No. 4, se evidenció la pertinencia de cada una de las partes del texto:

\section{¡Por la educación presencial!}

Hola, Mi nombre es María Fernanda Ceballos del grado quinto B. Soy conocedora de sus necesidades, de sus deseos y realidades y también de la problemática que se vive a nivel mundial por causa del Covid - 19. Como estudiante quiero que todos los niños puedan estudiar presencialmente, cumpliendo con las medidas de protección contra este virus que nos afecta. Yo creo que la educación presencial es mejor; porque comprendemos mucho más los temas, ya que tenemos profesores para que nos expliquen. Las clases virtuales nos dejan muchas dudas, nos sentimos frustrados, perdidos. Se pierde el objetivo de lo que los maestros nos quieren enseñar. Por ello, para asistir presencialmente propongo hablar con los directivos del colegio y formar un plan de bioseguridad y entregar a los estudiantes un kit que contenga: gel antibacterial y guantes. Además, propongo cumplir con el distanciamiento mediante dos jornadas; mañana y tarde, y en el descanso habilitar el otro patio y crear unos horarios por grupos donde los profesores estén atentos a qué se cumplan las normas. Esto para evitar aglomeraciones. En conclusión, les recuerdo compañeros que la educación presencial es garantía de una educación de calidad, sin olvidar que en este tiempo de pandemia que ser cuidadosos normas de bioseguridad crear por las directivas del plantel. Queridos compañeros apoyen mi propuesta y tendremos un futuro mejor en la educación.

Como se observa en el extracto anterior, además de la pertinencia de cada una de las partes, se tuvo en cuenta el uso de mecanismos de coherencia textual, a saber: (1) Función persuasiva de la tesis, (2) Relación lógica entre argumentos y función persuasiva de la tesis, (3) Relación de la conclusión con la función socio-pragmática persuasiva electoral y (4) Relación de la conclusión con la tesis.

- Microestructura. Uso excedido e incorrecto de comas y de puntos y coma. Ausencia de marcadores textuales, persistiendo la yuxtaposición de frases. 
En la última categoría (Desempeño en el uso de mecanismos de persuasión), los resultados, en función del mecanismo focalizado, fueron:

- Ethos. Los estudiantes construyeron una autoimagen confiable en su discurso, permitiéndoles prever su influencia en la audiencia y ganar su confianza

- Pathos. Se observó el uso de un discurso estratégico político y de liderazgo, focalizado en conseguir la adhesión del auditorio, moviéndolo a la acción, es decir, al voto mediante el establecimiento de afinidad con las emociones, las pasiones de dicho auditorio y la inscripción de la afectividad en el lenguaje empleado. Para ganar empatía con el auditorio, identificamos el uso de mecanismos retóricos, entre otros, la ironía y la rima, tal como lo ejemplifican los siguientes textos multimodales, tomados del portafolio del estudiante, en el desarrollo de la Unidad No. 4, tal como se presenta en la Figura 2.

Fuente: elaboración propia

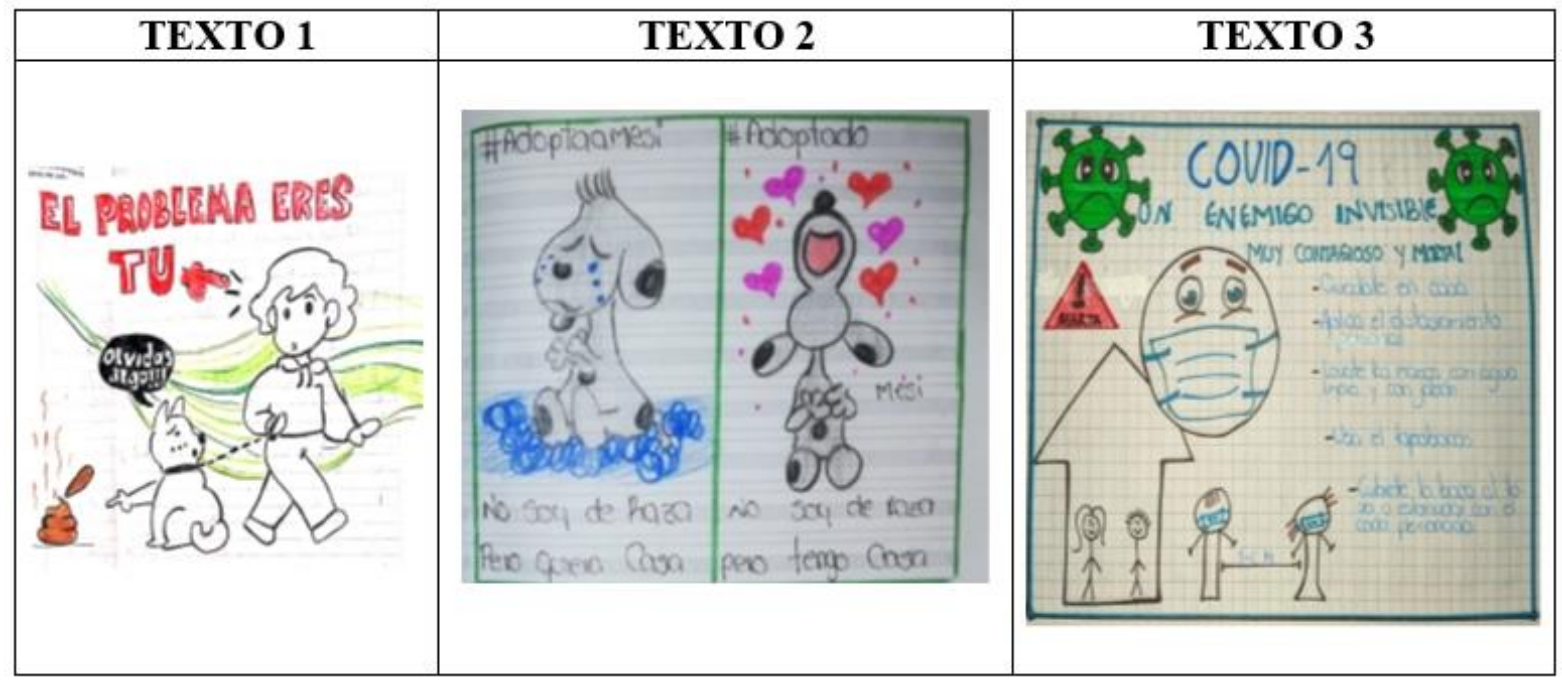

Figura 2. Uso de mecanismos retóricos en textos multimodales del portafolio de los estudiantes

- Logos. Identificamos falencias en: distinción entre la voz e idea del autor y la voz de las fuentes y argumentos de autoridad.

La entrevista a la docente mostró la estrategia metacognitiva de enseñanza relativa a la valoración del uso de la estructura textual y mecanismos de persuasión de la propuesta electoral solicitada, dado que la docente validó la naturaleza de los textos elaborados por los estudiantes, encontrando los mecanismos del texto persuasivo en ellos. El siguiente extracto documenta dicha valoración:

Mm...Algunos niños todavía tienen dificultades para comprender qué es la persuasión. /// confunden la parte que tiene que ver con cambiarle la opinión a la otra persona con argumentos valederos. Sin embargo, están los niños que comprenden con rapidez $\rightarrow$ y han pasado de basarse en definiciones del diccionario o del internet y ya han elaborado su propia definición de 
persuasión. Se ve que ... hay niños que sí han interiorizado, preguntan por la calidad de los argumentos...si realmente están persuadiendo y moviendo las emociones e interés del público.

\section{Evaluación del Impacto de la Secuencia Didáctica Metacognitiva}

La evaluación del impacto de la implementación de la secuencia didáctica con enfoque metacognitivo tuvo como fuente la prueba final, en la cual participaron 27 estudiantes. Presentamos los resultados respectivos en relación con los niveles de la organización discursiva (super, macro y microestructura) y con el uso de los mecanismos de persuasión del ethos, pathos y logos. La estadística descriptiva fue la siguiente: primero, la proporción corresponde al porcentaje de observaciones con una característica en particular entre la población de referencia. Se utilizó para valorar el impacto de la secuencia didáctica metacognitiva sobre las medidas superestructurales, siendo estas variables numéricas. Segundo, la mediana, medida de tendencia central y propia de los niveles de medición ordinal (escala de Likert, en la presente investigación), se utilizó para valorar el impacto respectivo sobre las medidas macro y microestructurales, así como sobre el uso de los mecanismos de persuasión (medidas cualitativas, y no numéricas). La estadística inferencial, en el caso de las proporciones, fue la prueba de hipótesis de comparación de proporciones y la prueba de KruskalWallis, en el caso de las medidas cualitativas.

Evaluación del Impacto sobre las Medidas Superestructurales

La Tabla 3 contiene los resultados del impacto de la secuencia didáctica implementada sobre las cuatro medidas de evaluación del nivel superestructural del texto argumentativo focalizado.

Tabla 3. Impacto de la secuencia didáctica con enfoque metacognitivo sobre la superestructura del texto argumentativo persuasivo de carácter electoral

\begin{tabular}{lcccc}
\hline \multicolumn{1}{c}{ Medidas de evaluación } & $\begin{array}{c}\text { Proporciones } \\
\text { de la prueba } \\
\text { diagnóstica } \\
(\mathrm{n}=37)\end{array}$ & $\begin{array}{c}\text { Proporciones } \\
\text { de la prueba de } \\
\text { final } \\
(\mathrm{n}=27)\end{array}$ & $\begin{array}{c}\text { Prueba de hipótesis de } \\
\text { comparación de proporciones* }\end{array}$ \\
\cline { 3 - 5 } $\begin{array}{l}\text { Naturaleza argumentativa } \\
\text { persuasiva electoral }\end{array}$ & 84 & 95 & $\begin{array}{c}\text { Valor } \\
\text { estadístico }\end{array}$ & Valor de $P$ \\
$\begin{array}{l}\text { Planteamiento de la tesis } \\
\begin{array}{l}\text { Argumentos desarrollados } \\
\text { en sustento de la tesis }\end{array}\end{array}$ & 38 & 45 & -1.261 & 0.103 \\
$\begin{array}{l}\text { Enunciación de la } \\
\text { conclusión }\end{array}$ & 84 & 95 & -0.529 & 0.298 \\
\hline
\end{tabular}

"El nivel de significancia fijado corresponde a 0.05

Fuente: Elaboración propia

La prueba de hipótesis de comparación de proporciones reveló que la secuencia didáctica metacognitiva se implementó sin haber producido mejoras en los desempeños de cada una de las mediciones superestructurales. Sin embargo, en la 
distribución muestral, al finalizar la respectiva implementación, se observaron mejoras en cada una de dichas medidas.

\section{Evaluación del Impacto sobre las Medidas Macroestructurales}

Los resultados sobre el impacto de la implementación de la secuencia didáctica metacognitiva sobre las medidas macroestructurales del texto argumentativo se presentan en la Tabla 4.

Tabla 4. Impacto de la secuencia didáctica metacognitiva sobre la macroestructura del texto argumentativo persuasivo de carácter electoral

\begin{tabular}{|c|c|c|c|c|}
\hline \multirow{2}{*}{ Medidas de evaluación } & \multirow{2}{*}{$\begin{array}{l}\text { Mediana Prueba } \\
\text { diagnóstica } \\
(\mathrm{n}=37)\end{array}$} & \multirow{2}{*}{$\begin{array}{l}\text { Mediana } \\
\text { Prueba final } \\
\quad(n=27)\end{array}$} & \multicolumn{2}{|c|}{$\begin{array}{l}\text { Prueba de Kruskal- } \\
\text { Wallis* }\end{array}$} \\
\hline & & & $\begin{array}{c}\text { Valor } \\
\text { estadístico }\end{array}$ & Valor de $P$ \\
\hline $\begin{array}{l}\text { Función socio-pragmática } \\
\text { persuasiva electoral }\end{array}$ & 3 & 5 & 9.90342 & 0.002 \\
\hline Función persuasiva de la tesis & 0 & 0 & 1.90771 & 0.167 \\
\hline $\begin{array}{l}\text { Relación lógica entre argumentos } \\
\text { y función socio-pragmática } \\
\text { persuasiva electoral }\end{array}$ & 3 & 5 & 13.8105 & 0.002 \\
\hline $\begin{array}{l}\text { Relación lógica entre argumentos } \\
\text { y función persuasiva de la tesis }\end{array}$ & 0 & 1 & 6.7495 & 0.009 \\
\hline $\begin{array}{l}\text { Coherencia entre argumentos } \\
\text { desarrollados }\end{array}$ & 3 & 5 & 3.14557 & 0.034 \\
\hline $\begin{array}{l}\text { Relación de la conclusión con la } \\
\text { Función socio-pragmática } \\
\text { persuasiva electoral }\end{array}$ & 0 & 2 & 6.37203 & 0.012 \\
\hline $\begin{array}{l}\text { Relación de la conclusión con la } \\
\text { tesis persuasiva }\end{array}$ & 0 & 0 & 7.36396 & 0.312 \\
\hline
\end{tabular}

${ }^{*}$ El nivel de significancia fijado corresponde a 0.05

Fuente: Elaboración propia

La Tabla 4 reveló que el impacto de la secuencia didáctica metadiscursiva sobre la macroestructura de la propuesta electoral evaluada fue diferencial, es decir, dependió de las medidas de evaluación involucradas. Este comportamiento diferencial se observó en tres aspectos. Primero, mejoras observadas en cinco medidas de siete: (1) Función socio-pragmática persuasiva electoral, (2) Relación lógica entre argumentos y función socio-pragmática persuasiva electoral, (3) Relación lógica entre argumentos y función persuasiva de la tesis, (4) Coherencia entre argumentos desarrollados y (5) Relación de la conclusión con la Función socio-pragmática persuasiva electoral. Segundo, identificación de necesidades. A pesar de las mejoras observadas, la muestra poblacional aún necesita continuar mejorando el dominio de la relación lógica entre argumentos y la función persuasiva de la tesis, así como la Relación de la conclusión con la Función socio-pragmática persuasiva electoral. 
Finalmente, ausencia de mejoras en la función persuasiva de la tesis y en la relación de la conclusión con la tesis persuasiva.

\section{Evaluación del Impacto sobre las Medidas Microestructurales}

Los resultados sobre el impacto de la secuencia didáctica implementada sobre las medidas de evaluación de la microestructura del texto argumentativo persuasivo de carácter electoral se presentan en la Tabla 5.

Tabla 5. Impacto de la secuencia didáctica metacognitiva sobre la microestructura del texto argumentativo persuasivo de carácter electoral

\begin{tabular}{|l|c|c|c|c|}
\hline \multicolumn{1}{|c|}{ Medidas de evaluación } & \multirow{2}{*}{$\begin{array}{c}\text { Mediana } \\
\text { Prueba } \\
\text { diagnóstica } \\
(\mathrm{n}=37)\end{array}$} & $\begin{array}{c}\text { Mediana } \\
\text { Prueba final } \\
(\mathrm{n}=27)\end{array}$ & \multicolumn{2}{|c|}{$\begin{array}{c}\text { Prueba de Kruskal- } \\
\text { Wallis }\end{array}$} \\
\cline { 4 - 5 } & 3 & 4 & 4,90203 & 0.032 \\
\hline $\begin{array}{l}\text { Mecanismos de unión de las ideas: } \\
\text { función argumentativa de los } \\
\text { marcadores textuales }\end{array}$ & 3 & 3 & 2,92194 & 0.082 \\
\hline $\begin{array}{l}\text { Mecanismos de cohesión léxica: } \\
\text { repetición, la reiteración y la } \\
\text { asociación }\end{array}$ & 3 & 3 & 6,88543 & 0.008 \\
\hline $\begin{array}{l}\text { Relaciones entre las ideas por medio } \\
\text { de los signos de puntuación }\end{array}$ & 2 & 5 & 13,0718 & 0.0003 \\
\hline $\begin{array}{l}\text { Relación lógica entre las palabras } \\
\text { que conforman una frase: }\end{array}$ & 3 & & & \\
\hline
\end{tabular}

${ }^{*}$ El nivel de significancia fijado corresponde a 0.05

Fuente: Elaboración propia

La Tabla 5 reveló mejoras en los siguientes mecanismos locales y superficiales que hacen que la propuesta electoral, tipificada como argumentativa y persuasiva, sea cohesiva y coherente: marcadores textuales, signos de puntuación y concordancia gramatical. Reveló, igualmente, que el desempeño Aceptable, diagnosticado en los mecanismos de cohesión léxica (repetición, reiteración y asociación), permaneció intacto en la prueba final.

\section{Evaluación del Impacto sobre los Mecanismos de Persuasión}

La Tabla 6 presenta los resultados del impacto de la secuencia didáctica metacognitiva sobre los mecanismos de persuasión identificados en el texto argumentativo persuasivo de carácter electoral. 
Tabla 6. Impacto de la secuencia didáctica metacognitiva sobre los mecanismos de persuasión del texto argumentativo persuasivo de carácter electoral

\begin{tabular}{|l|c|c|c|c|}
\hline \multirow{2}{*}{ Modos de persuasión } & \multirow{2}{*}{$\begin{array}{c}\text { Mediana Prueba } \\
\text { diagnóstica } \\
(n=37)\end{array}$} & $\begin{array}{c}\text { Mediana Prueba } \\
\text { de final } \\
(n=27)\end{array}$ & \multicolumn{2}{|c|}{ Prueba de Kruskal-Wallis* } \\
\cline { 4 - 5 } & & 3.0 & 0.873178 & 0.350 \\
\hline Ethos & 3.0 & 3.0 & 1.43929 & 0.230 \\
\hline Pathos & 3.0 & 1.0 & 9.98849 & 0.061 \\
\hline Logos & 1.0 & & Valor & \\
\hline
\end{tabular}

"El nivel de significancia fijado corresponde a 0.05

Fuente: Elaboración propia

Según la Tabla 6, las hipótesis de investigación acción acerca del impacto positivo de la implementación de la secuencia didáctica metacognitiva sobre los niveles de desempeño en los mecanismos de persuasión del ethos, pathos y logos fueron nulas. Seguidamente, los datos en el contexto de la muestra poblacional de la presente investigación revelaron que dicha muestra logró el nivel de desempeño Aceptable en los dos mecanismos de persuasión ligados a los sentimientos (ethos y pathos), mientras que hubo carencias en el uso de argumentos ligados al logos: nivel de desempeño de Deficiente.

En resumen, de la anterior presentación de resultados, concluimos que el 463 impacto de la implementación de la secuencia didáctica con enfoque metacognitivo sobre la construcción de la organización discursiva y el uso de mecanismos persuasivos del texto argumentativo persuasivo de carácter electoral, escrito en español/LM, de estudiantes de 5. grado de primaria de inmersión en inglés/L2 en una institución educativa pública de un municipio del Quindío, fue diferencial. La sustentación de dicha conclusión es la siguiente: (1) Ausencia de mejoras en el dominio de los cuatro mecanismos superestructurales focalizados, (2) Mejoras en cinco, de siete mecanismos macroestructurales (Función socio-pragmática persuasiva electoral, Relación lógica entre argumentos y función socio-pragmática persuasiva electoral, Relación lógica entre argumentos y función persuasiva de la tesis, Coherencia entre argumentos desarrollados y Relación de la conclusión con la Función sociopragmática persuasiva electoral) (3) Mejoras en tres, de cuatro mecanismos microestructurales (Marcadores textuales, Signos de puntuación y Concordancia gramatical) y (4) Ausencia de mejoras en el dominio de los tres mecanismos persuasivos.

\section{Discusión}

Los autores del artículo discuten los resultados, anteriormente presentados, teniendo en cuenta el ciclo de la investigación-acción desarrollada según sus fases de diagnóstico, seguimiento a la acción y evaluación. En primer lugar, hallamos en la fase diagnóstico que la muestra poblacional objeto tendría que realizar esfuerzos para mejorar, por un lado, el dominio de la organización del discurso, en cuanto a la 
superestructura, macroestructura y microestructura y, por el otro, el uso de mecanismos persuasivos atinentes al ethos, pathos y logos, en la producción escrita en español/LM con enfoque argumentativo persuasivo y electoral. El marco interpretativo del diagnóstico anterior, propuesto por los autores del artículo, es el siguiente: primero, pese a ser la argumentación reconocida como "uno de los fundamentos de la vida en sociedad" (Del caño, 1999), dicha muestra poblacional confronta dificultades en la comprensión y uso de mecanismos que aseguran la calidad argumentativa persuasiva electoral en el plano global y local, así como en la producción de argumentos de validez en el ámbito del pathos, ethos y logos. Segundo, la proporción de aciertos del $84 \%$ (31 casos de 37 observados) en la medida de evaluación de carácter eliminatorio (Naturaleza argumentativa persuasiva electoral), desde la teoría socio-constructivista de Vygotsky (1978), indicaría que la muestra poblacional puso en escena sus conocimientos previos al escribir dichas propuestas, con el fin de lograr la adhesión del auditorio frente a la tesis electoral expuesta. En efecto, plantea Vygotsky, todo aprendizaje en la escuela siempre tiene una historia previa, por lo tanto, aprendizaje y desarrollo están interrelacionados desde los primeros días de vida del niño. Al mismo tiempo, tal hallazgo sería una consecuencia del conocimiento intuitivo que poseería la muestra poblacional en referencia sobre la argumentación persuasiva, ya que dicha práctica discursiva está presente en la vida cotidiana de la humanidad en general $\mathrm{y}$, en particular, de la población infantil (Rodríguez Hernández et al., 2020). Finalmente, debido a las carencias observadas en los niveles macro y microestructurales de la producción escrita focalizada, el texto en su conjunto sería percibido como una sucesión de enunciados incoherentes (Van Dijk, 2005).

En segundo lugar, hallamos en la fase de acción y seguimiento a la implementación de la secuencia didáctica metacognitiva que en cuanto a la categoría comportamiento metacognitivo en la producción escrita en español/LM de una propuesta electoral con enfoque argumentativo persuasivo, la habilidad de autoevaluación y reflexión sobre los procesos comunicativos demostrada por los estudiantes sería el resultado de la articulación de estrategias de enseñanza metacognitivas y la puesta en escena de ejercicios metacognitivos para la escritura de la propuesta electoral focalizada. En lo correspondiente a la Activación de conocimientos previos observada, postulamos que el fomento de dicha habilidad metacognitiva permite al estudiante conocer su percepción, relevancia e implicaciones de lo que aprende. Su fomento obedecería a la percepción de la argumentación persuasiva electoral de la docente, según la cual la producción escrita de textos argumentativos persuasivos con enfoque electoral juega un papel importante en la vida diaria y académica del estudiante. El Ordenamiento y secuenciación evidenciados en las actividades metacognitivas, se fundamentaría en que el sujeto que emplea la organización logra estructurar no solo aspectos globales de la tarea como sus tiempos, objetivos, metas, tareas o actividades y de esta manera llevarlos a cabo de forma adecuada, sino también aspectos específicos al interior de la tarea. Estos autores manifiestan que, al permitirle al estudiante usar dicha habilidad y estrategia metacognitiva se logra fijar el conocimiento del tema estudiado y 
ejemplificarle al estudiante la jerarquía que debe presentar, identificando los conceptos, palabras, enlaces, proposiciones y conexiones cruzadas (Huertas et al., 2014). Respecto al avance observado en el uso de habilidades metacognitivas en el Proceso metacognitivo de escritura (planeación, textualización y revisión) y Análisis y uso metapragmático de los mecanismos de persuasión, Núñez (2019) plantea que la reflexión y la consciencia metacognitiva da muestra de la capacidad que posee un sujeto para establecer relaciones entre un mensaje lingüístico oral y su contexto extralingüístico. Por otra parte, en la categoría Desempeño en la construcción de la estructura textual, el uso de la super, macro y micro estructuras en los textos obedecerían a la comprensión que habrían desarrollado los estudiantes de la escritura como un proceso significativo en el que hay interrelación de todas las partes para lograr un objetivo final y, por lo demás, donde el escritor debe mantener un diálogo constante entre el propósito del ejercicio de escritura y su ejecución. En efecto, la implementación de estrategias de enseñanza como la interrogación y la discusión metacognitiva, habría generado hábitos y habilidades de regulación y monitoreo que aseguraron la evaluación de la calidad de las ideas, la coherencia entre estas y la función persuasiva electoral de la propuesta escrita. Finalmente, en la última categoría, Desempeño en el uso de mecanismos de persuasión se observó el uso del ethos y el pathos. Al respecto Barajas et al. (2019) manifiestan que, en la medida en que la persuasión logra algún efecto en otra persona, es razonable suponer que el persuasor recurre a su conocimiento cognitivo social. Sin embargo, con respecto al logos se requeriría mayor instrucción y reflexión metacognitiva en el uso de este tipo de argumentos, de tal manera que los estudiantes, escritores de propuestas electorales argumentativas persuasivas, puedan hacer uso retórico de las citas que sustenten su propia voz, emitir evaluaciones fundamentadas $\mathrm{y}$ reconocer las posiciones alternativas a las cuales pueden adherirse o confrontar (Bañales et al., 2015).

Finalmente, en lo relativo a la evaluación del impacto de la secuencia didáctica metacognitiva, hallamos que dicho impacto fue de naturaleza diferencial. La discusión de dicho hallazgo es la siguiente:

- Observamos ausencia de mejoras en el dominio de los cuatro mecanismos superestructurales focalizados. Sin embargo, en la distribución muestral, al finalizar la respectiva implementación, se observaron mejoras en cada una de dichas medidas. Teniendo en cuenta tales mejoras, hipotetizamos que la muestra poblacional habría avanzado hacia la consolidación de la argumentación como una macrofunción de la lengua natural, que incorpora tres funciones básicas, definidas por Cuenca (1995): la expresiva (manifiesta la opinión del emisor); la apelativa (intenta incidir sobre el receptor) y la representativa (nos habla sobre el mundo). Del mismo modo, casi la mitad de la muestra poblacional, en particular, el $45 \%$ aún necesitaría mejorar sus conocimientos en estructuras globales que aseguran el orden global del texto, como diría Van Dijk (2005), en particular, el planteamiento de la tesis y la enunciación de la conclusión. Seguidamente, en contextos educativos, 
orientados en LM, investigaciones antecedentes revelaron que la implementación de secuencias didácticas, centradas en distintas acciones, entre ellas, el propósito comunicativo y la organización del contenido, mejoró los desempeños en mecanismos que aseguran el esquema argumentativo básico de textos con enfoque persuasivo, escritos en LM (Hidalgo et al., 2019; Rodríguez Hernández et al., 2020; Sánchez y Silva, 2011). Tales antecedentes contradecirían los resultados, aquí reportados, del impacto de una secuencia didáctica metacognitiva sobre la organización superestructural de una propuesta electoral con enfoque de la argumentación persuasiva, escrita en español/LM, por estudiantes escolarizados en L2, principalmente, en educación bilingüe por inmersión en inglés/L2.

- Constatamos mejoras en cinco de siete mecanismos macroestructurales (Función socio-pragmática persuasiva electoral, Relación lógica entre argumentos y función socio-pragmática persuasiva electoral Relación lógica entre argumentos y función persuasiva de la tesis, Coherencia entre argumentos desarrollados y Relación de la conclusión con la Función sociopragmática persuasiva electoral). Las debilidades observadas, al final de la intervención didáctica en referencia, en cuatro medidas macroestructurales (Función persuasiva de la tesis, relación lógica entre argumentos y función persuasiva de la tesis, relación de la conclusión con la Función sociopragmática persuasiva electoral y relación de la conclusión con la tesis persuasiva), disminuirían, según nuestra óptica, la fuerza argumentativa persuasiva electoral. Desde la nueva retórica, la función persuasiva de la argumentación consiste en producir o acrecentar la adhesión de un auditorio a la tesis que se presenta a su asentimiento (Perelman, 1977/1997; Perelman y Olbrechts-Tyteca, 1966/1989). Del mismo modo, bajos niveles de fuerza argumentativa electoral implicarían menos validez del discurso electoral: "La persuasión no se desarrolla jamás en el vacío" (Perelman, 1977/1997, p. 29). Por lo demás, para todo locutor, según Perelman, existe un interlocutor activo, y a más grado de adhesión entre los partícipes, más válido será el discurso de quien pretende influir en el intérprete. Asimismo, el autor en referencia, planteó que "la argumentación no tiene por fin únicamente la adhesión puramente intelectual: ella busca muy a menudo, incitar a la acción, o por lo menos, crear una disposición a la acción" (p. 32). En tal sentido, si la fuerza persuasiva electoral se debilita, el discurso perdería poder para incitar a la acción, que consiste, en el caso de la presente investigación, en el voto a favor.

- Hallamos mejoras en tres de cuatro mecanismos microestructurales (Marcadores textuales, Signos de puntuación y Concordancia gramatical). Investigadores en lingüística textual, entre ellos Van Dijk (1978/1992), Calsamiglia y Tusón (1999) y Aguillón y Palencia (2004), consideraron que los mecanismos microestructurales, además de unir las ideas del texto de manera cohesiva y coherente, guían al lector en la comprensión del significado del texto. Desde este enfoque, y teniendo en cuenta las mejoras observadas, las 
propuestas electorales de carácter argumentativo y persuasivo, escritas en español/LM por la muestra poblacional en mención, contendrían guías que ayudarían a sus lectores no solo a comprender las relaciones entre las proposiciones que conforman el mensaje electoral expuesto, sino también a fortalecer la continuidad temática argumentativa persuasiva electoral; lo que podría llevar al lector a adherirse a la tesis expuesta.

- Observamos ausencia de mejoras en el dominio de los tres mecanismos persuasivos. No obstante, los datos en el contexto de la muestra poblacional de la presente investigación revelaron que dicha muestra logró el nivel de desempeño Aceptable en los dos mecanismos de persuasión ligados a los sentimientos (ethos y pathos), mientras que hubo carencias en el uso de argumentos ligados al logos: nivel de desempeño de Deficiente. En dicho contexto, la persuasión vista, según Austin (1962), desde su teoría de los actos de habla como un acto perlocucionario, tiene la tendencia a privilegiar la argumentación ligada a los sentimientos, tanto del argumentador como del auditorio. Creemos, del mismo modo que, en este contexto, el discurso político con enfoque argumentativo persuasivo sería una práctica social que privilegia los sentimientos sobre la razón. Investigadores de la persuasión, puesta en el corazón de la argumentación, entre ellos, Aristóteles (1990) y Perelman y Olbrechts-Tyteca (1966/1989), sostienen que los usuarios del lenguaje cuyo objetivo es incitar a sus interlocutores a hacer, a decir o a adherirse a una tesis expuesta estarían más preocupados por el impacto de su discurso que por el rigor de su razonamiento.

\section{CONCLUSIONES}

La investigación aquí reportada fue de corte cualitativo y con diseño de investigaciónacción. Evaluó el impacto de la implementación de una secuencia didáctica con enfoque metacognitivo sobre la construcción de la organización discursiva y el uso de mecanismos persuasivos en la producción argumentativa persuasiva de carácter electoral, escrita en español/LM, de estudiantes de 5. grado de primaria pública en inmersión en inglés/L2 de un municipio del departamento del Quindío. De la evaluación del impacto de su implementación hallamos que el impacto tanto en las medidas de organización del discurso argumentativo como en las medidas de uso de los mecanismos persuasivos, fue de naturaleza diferencial; esto es, dependió de las medidas de evaluación involucradas. Lo anterior indica que la secuencia didáctica implementada mejoró en los estudiantes el dominio de varios mecanismos de la organización textual y de persuasión. De este hallazgo concluimos que, si algún mecanismo de aseguramiento de la construcción discursiva se deteriora, el lector tendría dificultades para comprender los significados de la propuesta electoral y su adhesión a la tesis electoral expuesta podría afectarse. Ciertamente, como lo señalamos en el presente documento, los niveles de la organización del discurso se convierten en guía para que el lector pueda inferir los significados a través del 
discurso desarrollado (Kintsch y Van Dijk, 1978; Van Dijk, 1978/1992, 2005). Del respectivo seguimiento a la implementación se encontró el comportamiento metacognitivo en la producción escrita en español/LM del texto argumentativo persuasivo de carácter electoral, el uso de la estructura textual y de los mecanismos de persuasión. De lo anterior concluimos que la implementación de las estrategias de enseñanza metacognitiva (modelamiento cognitivo y metacognitivo, interrogación metacognitiva y discusión metacognitiva) permiten al estudiante, por un lado, elaborar textos pertinentes en su dimensión organizacional y socio-pragmática y, por el otro, concebir dicha práctica como una actividad comunicativa y significativa en su entorno socio-educativo.

Por otra parte, para proyectar la presente investigación-acción proponemos la ejecución de un nuevo ciclo de la espiral autorreflexiva, consistente en ajustar el plan implementado a la luz de la información obtenida (Efron y Ravid, 2020; Elliot, 2000). En la presente investigación, el plan de acción respectivo concernió el modelamiento e implementación de una secuencia didáctica metacognitiva para mejorar la argumentación persuasiva en la producción escrita en español/LM de una propuesta electoral, en estudiantes de 5. grado de primaria pública por inmersión en inglés/L2. Por otra parte, "el pensador crítico presenta cuatro habilidades fundamentales: argumentación, análisis, solución de problemas y evaluación" (Cangalaya, 2020, p. 146). En concordancia con lo planteado por Cangalaya, el ajuste a la intervención didáctica metacognitiva sobre la producción escrita en español/LM de una propuesta electoral, argumentativa y persuasiva incluiría acciones encaminadas a potenciar la argumentación y a desarrollar las habilidades restantes del pensamiento crítico: análisis, solución de problemas y evaluación.

Finalmente, las limitaciones de la presente tuvieron que ver con los inconvenientes causados por la emergencia sanitaria debido a la COVID-19. Esta generó diversos cambios en el proceso investigativo: (1) Redujo la población inicial de 37 a 27 participantes, principalmente, por problemas de conectividad y acceso al material didáctico, (2) Demandó la adecuación de la implementación del plan de acción, obligando a realizar una adaptación de los procesos metodológicos y de seguimiento. Específicamente, se hizo una transición de una intervención didáctica presencial a una intervención virtual. Esta dificultad se pudo sobrepasar gracias a la mediación permitida por las herramientas tecnológicas como el WhatsApp, la plataforma educativa Integratic y el software de video chat Zoom.

\section{REFERENCIAS}

Aguillón, P., y Palencia, P. (2004). Características del discurso escrito de los estudiantes que cursan lenguaje en educación a distancia en LUZ-COL. Lingua Americana, 8(15), 81-97.

Aristóteles. (1990). Retórica. Gredos.

Austin, J.L. (1962). How to do things with words. The William James Lectures delivered at Harvard University in 1955. Oxford University Press. 
Austin, J., Blume, M., y Sánchez, L. (2015). Bilingualism in the Spanish-Speaking World. Linguistic and Cognitive Perspectives. Cambridge University Press.

Baker, C., y Wright, W.E. (2017). Foundations of Bilingual Education and Bilingualism (6 ${ }^{\text {th }}$ ed.). Multilingual Matters.

Bañales, G., Vega, N., Alvineda, N., Valladares, A., y Rodríguez, B. (2015). La enseñanza de la argumentación escrita en la universidad: Una experiencia de intervención con estudiantes de Lingüística aplicada. Revista Mexicana de Investigación Educativa, 20(66), 879-910. https://www.comie.org.mx/revista/v2018/rmie/index.php/nrmie/article/view/15 0 .

Barajas, C., Linero, M., y Cedeño, C. (2019). Habilidades de persuasión en niños y niñas de 6 a 12 años. El papel de la teoría de la mente y de la competencia lingüística. International Journal of Developmental and Educational Psychology, 2(1), 85-98. https://doi.org/10.17060/ijodaep.2019.n1.v2.1405.

Bartsch, K., y London, K. (2000). Children's use of mental state information in persuasive arguments. Developmental Psychology, 36(3), 352-365. https://doi.org/10.1037//0012-1649.36.3.352.

Brassart, D. (1995). Elementos para una didáctica de la argumentación en la escuela primaria. Comunicación, Lenguaje y Educación, 7(2), 41-50. https://doi.org/10.1174/021470395321340420.

Bejarano, D., Llanos, A., Rubio, R., y Bonilla, J. (2018). Protocolo de transcripción ortográfica CLICC. https://bit.ly/2UQZdHT.

Benítez, T. (2011). Investigating Difficulties in Elementary School Students' Written Expression. Zona Próxima, (14), 28-53. https://rcientificas.uninorte.edu.co/index.php/zona/article/view/89.

Calsamiglia, H., y Tusón, A. (1999). Las cosas del decir. Manual de análisis del discurso. Editorial Ariel.

Camps, A., y Dolz, J. (1995). Enseñar a argumentar: un desafío de la escuela actual. Comunicación, Lenguaje y Educación, (25), 5-8.

Cangalaya, L. (2020). Habilidades del pensamiento crítico en estudiantes universitarios a través de la investigación. Desde el Sur, 12(1), 141-153. https://doi.org/10.21142/DES-1201-2020-0009.

Cardete, M.J., Curiel. J., y Antonovica, A. (2019). La comunicación persuasiva en política como elemento fundamental en el éxito de nuevas formaciones políticas en España: emisor, mensaje y contexto. Caso Podemos y Ciudadanos. Estudios sobre el Mensaje Periodístico, 26(1), 59-69. https://doi.org/10.5209/esmp.67286.

Charaudeau, P. (2009). La argumentación persuasiva. El ejemplo del discurso político. En M. Shiro, P. Bentivoglio y F.D. Erlich (Comps.), Haciendo discurso. Homenaje a Adriana Bolívar (pp. 277-295). Universidad Central de Venezuela.

Chaverra, D. (2011). Las habilidades metacognitivas en la escritura digital. Revista Lasallista de Investigación, $8(2)$, 104-111. http://repository.lasallista.edu.co:8080/ojs/index.php/rldi/article/view/39. 
Cisterna, F. (2005). Categorización y triangulación como procesos de validación del conocimiento en investigación cualitativa. Theoria, 14(1), 61-71.

Congreso de la República de Colombia. (1994). Ley 115. Diario Oficial N 41.214. Santafé de Bogotá D.C., Colombia, 08 de febrero de 1994.

Constitución política de Colombia. (1991). Gaceta Constitucional número 114. http://www.suinjuriscol.gov.co/viewDocument.asp?ruta=Constitucion/1687988.

Cuenca, M. (1995). Mecanismos lingüísticos y discursivos de la argumentación. Comunicación, Lenguaje y Educación, 7(2), 23-40. https://doi.org/10.1174/021470395321340411.

Del Caño, A. (1999). Los géneros orales informativos. En S. Alcoba (Coord.), La oralización (pp. 109-168). Ariel.

Díaz Barriga, Á. (2013). Secuencia de aprendizaje. ¿Un problema del enfoque de competencias o un reencuentro con perspectivas didácticas? Profesorado, 17(13), 11-33. http://hdl.handle.net/20.500.12424/1349156.

Efron, S., y Ravid, R. (2020). Action research in education: a practical guide (2 ${ }^{\text {nd }}$ Edition). The Guilford Press.

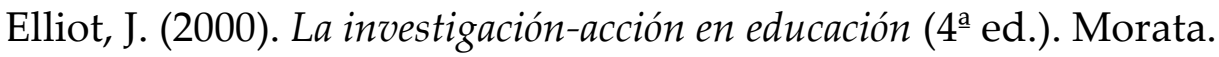

Esteves, Z., Navarrete, R., y García, M. (2020). Instrumento alternativo para la evaluación del proceso enseñanza- aprendizaje en la educación básica general. Publicaciones, 50(2), 121-132. https://doi.org/10.30827/publicaciones.v50i2.13948.

Fernández, T., y López, M. (2020). Análisis de los mecanismos persuasivos del ethos, logos y pathos en los discursos de Pedro Sánchez y Pablo Casado en el debate de investidura (España, 4 de enero de 2020). Discurso $\mathcal{E}$ Sociedad, 14(1), 188-226. http://www.dissoc.org/ediciones/v14n01/DS14\%281\%29FernandezUlloaI.pdf.

Flavell, J.H. (1976). Metacognitive aspects of problem solving. En L.B. Resnik (Ed.), The nature of intelligence (pp. 231-235). Lawrence Erlbaum.

Galindo, A. (2002). Habiletés métasyntaxiques et production de textes argumentatifs écrits en langue maternelle d'élèves en début de secondaire en immersion et en classe régulière [Tesis de doctorado no publicada]. Université Laval, Québec, Canadá.

Galindo, A., y Moreno, L. (2019). Educación bilingüe (español-español) en tres instituciones educativas públicas del Quindío, Colombia: estudio de caso. Lenguaje, 47(2S), 648-684. https://doi.org/10.25100/lenguaje.v47i3.6906.

Galindo, A., y Moreno, L. (2020). Secuencia didáctica metadiscursiva para el desarrollo del ensayo argumentativo escrito en inglés de estudiantes de Licenciatura en $\begin{array}{llll}\text { Lenguas } \quad \text { Extranjeras. } & \text { 239-327. }\end{array}$ https://doi.org/10.25100/lenguaje.v48i2.8382.

Giménez, G., Stancato, C., Subtil, C., Colafigli, L., Reinaldi, A., Cacciavillani, C., y Maina, M. (2014). Opinar y decir lo propio: Estrategias para enseñar a argumentar en la Escuela. https://ansenuza.unc.edu.ar/comunidades/handle/11086.1/861. 
Guzmán-Cedillo, Y., y Flores, R. (2020). La competencia argumentativa como meta en contextos educativos. Revisión de la literatura. Educar, 56(1), 15-34. https://doi.org/10.5565/rev/educar.1009.

Hayes, J.R., y Flower, L.S. (1980). Identifying the Organization of Writing Processes. En L.W. Gregg y E.R. Steineberg (Eds.), Cognitive processes in writing (pp. 3-30). Lawrence Erbaum Associates.

Hayes, J.R., y Flower, L.S. (1986). Writing Research and the Writer. American Psychologist, 41(10), 1106-1113. https://psycnet.apa.org/doi/10.1037/0003066X.41.10.1106.

Hernández-Sampieri, R., y Mendoza, C.P. (2018). Metodología de la investigación. Las rutas cuantitativa, cualitativa y mixta. McGraw Hill.

Hidalgo, I., Ortiz de Santos, R., Santamaría-Cárdaba, N., y Ortega-Quevedo, V. (2019). La carta informal argumentativa: una secuencia didáctica de expresión y comprensión escrita en Educación Primaria. Didáctica. Lengua y Literatura, 31, 263-283. https://doi.org/10.5209/dida.65952.

Huertas, A., Vesga, G., y Galindo, M. (2014). Validación del instrumento 'inventario de habilidades metacognitivas (Mai)' con estudiantes colombianos. Praxis $\mathcal{E}$ Saber, 5(10), 55-74. https://doi.org/10.19053/22160159.3022.

Johnson, D.W., y Johnson, R.T. (1975). Learning Together and Alone: Cooperation, Competition and Individualization. Prentice Hall.

Kintsch, W., y Van Dijk, T.A. (1978). Toward a Model of Text Comprehension and $\begin{array}{llll}\text { Production. Psychological } & \text { Review, } & \text { 363-394. }\end{array}$ https://psycnet.apa.org/doi/10.1037/0033-295X.85.5.363.

Lawshe, C.H. (1975). A quantitative approach to content validity. Personnel Psychology, 28(4), 563-575. https://psycnet.apa.org/doi/10.1111/j.1744-6570.1975.tb01393.x.

Marín, L.A., Hernández R.E., y Flores, Q.J. (2016). Metodología para el análisis de datos cualitativos en investigaciones orientadas al aprovechamiento de fuentes renovables de Koinonía, 1(1), 60-75. https://www.fundacionkoinonia.com.ve/ojs/index.php/revistakoinonia/article/v iew/15.

Ministerio de Educación Nacional. (1998). Serie lineamientos curriculares Lengua Castellana. https://www.mineducacion.gov.co/1759/articles89869_archivo_pdf8.pdf.

Ministerio de Educación Nacional. (2006). Estándares Básicos de Competencias del Lenguaje. Recuperado de http://www.mineducacion.gov.co/1621/articles116042_archivo_pdf1.pdf.

Ministerio de Educación Nacional. (2017). Derechos Básicos de Aprendizaje: Lenguaje. https://aprende.colombiaaprende.edu.co/sites/default/files/naspublic/DBA_Len guaje.pdf.

Núñez, J. (2019). Análisis crítico del discurso como metodología de comprensión de las ideologías. Revista Innova Educación, 1(4), 505-521. https://doi.org/10.35622/j.rie.2019.04.007. 
O'Leary, A.P. (2017). Using Scaffolding to Examine The Development of Metacognitive Monitoring and Control [Tesis de doctorado]. The Ohio State University, Columbus, Estados Unidos. http://rave.ohiolink.edu/etdc/view?acc_num=osu1492172107513459.

Ovando, C.J., y Combs, M. (2018). Bilingual and ESL Classrooms. Teaching in Multicultural Contexts (6 $6^{\text {th }}$ ed.). Rowman \& Littlefield.

Paz Maldonado, E. (2018). La ética en la investigación educativa. Revista Ciencias Pedagógicas e Innovación, 6(1), 45-51. https://doi.org/10.26423/rcpi.v6i1.219.

Perelman, C. (1997). El imperio retórico: retórica y argumentación (Trad. A. Gómez). Grupo Editorial Norma. (Obra original publicada en 1977).

Perelman, C., y Olbrechts-Tyteca, L. (1989). Tratado de la argumentación: La nueva retórica (Trad. J. Sevilla). Gredos. (Obra original publicada en 1966).

Perelman, C. y Olbrechts-Tyteca, L. (2000). Traité de l'argumentation : la nouvelle rhétorique (5a ed.). Éditions de 1'Université de Bruxelles.

Piñuel, J. (2002). Epistemología, metodología y técnicas del análisis de contenido. Estudios de Sociolingüística, 3(1), 1-42. https://www.ucm.es/data/cont/docs/2682013-07-29-

Pinuel_Raigada_AnalisisContenido_2002_EstudiosSociolinguisticaUVigo.pdf.

Quintero, A., y Peña, O. (2016). El modelo metasociocognitivo. Una alternativa para situar la escritura en contexto [Tesis de maestría]. Universidad Distrital Francisco José de Caldas, Bogotá, Colombia. http://hdl.handle.net/11349/3404.

Rodríguez, B., Martínez, C., y Ruíz, N. (2020). Impacto de una secuencia didáctica para enseñar escribir artículos de opinión en primaria. Aula de Encuentro, 22(1), 163 193. https://doi.org/10.17561/ae.v22n1.7.

Sánchez, V., y Silva, M. (2011). Aprendiendo a argumentar. Análisis del uso de marcas enunciativas en cartas infantiles. Revista de Lingüística Teórica y Aplicada, 49(2), 129-151. http://dx.doi.org/10.4067/S0718-48832011000200007.

Slaughter, V., Peterson, C.C., y Moore, C. (2013). I can talk you into it: theory of mind and persuasion behavior in young children. Developmental Psychology, 49(2), 227231. https://doi.org/10.1037/a0028280.

Suárez Lantarón, B. (2018). Whatsapp: su uso educativo, ventajas y desventajas. Revista de Investigación en Educación, 16(2), 121-135. http://reined.webs.uvigo.es/index.php/reined/article/view/342.

To, C.K.S., Yim, S.F.Y., Lam, G.Y.H., y Iao, L.-S. (2016). Persuasion in Chinese SchoolAge Children With and Without Autism Spectrum Disorders. Focus on Autism and Other Developmental Disabilities, 31(3), 231-240. https://doi.org/10.1177\%2F1088357614547888.

Van Dijk, T.A. (1992). La ciencia del texto. Un enfoque interdisciplinario (Trad. S. Hunzinger). Ediciones Paidós. (Obra original publicada en 1978).

Van Dijk, T.A. (2005). Estructuras y funciones del discurso (14를 ed.). Siglo XXI.

Veenman, M. (2016). Metacognition and Individual Differences. In: P. Afflerbach (Ed.). Handbook of Individual Differences in Reading, Reader, Text, and Context (pp. 26-40). Routledge. 
Vygotsky, L.S. (1978). El desarrollo de los procesos psicológicos superiores. Grijalbo. Winne, P.H., y Azevedo, R. (2014). Metacognition. En R. Sawyer (Ed.), The Cambridge Handbook of the Learning Sciences (pp. 63-87). https://doi.org/10.1017/CBO9781139519526.006. 


\section{AneXos}

Anexo A: Prueba de escritura en español/LM del texto argumentativo persuasivo de carácter electoral

Código (Dejar en blanco)

Objetivo: Escribir un texto para explicar a tus compañeros por qué deben votar por ti para ser el representante de los grupos del grado $5^{\mathbf{o}}$ al Consejo Estudiantil de esta Institución Educativa.

Instrucciones: Imagina que quieres ser el representante de grado $5^{\circ}$ al Consejo Estudinatil. Sigue las siguientes instrucciones:

1. Lee el siguiente informe del rector:

"El rector de esta Institución Educativa informa que, en dos meses, convocará a los alumnos de los grupos del grado $5^{\circ}$ para elegir, por votación en una urna, un representante al Consejo Estudiantil. La inscripción de candidatos se realizará en su oficina".

2. Escribe un texto, explicando a tus compañeros por qué deben votar por ti, de tal manera que logres la mayor votación y puedas ser el representante de los grupos del grado $5^{\mathbf{o}}$ al Consejo Estudiantil.

3. Tú decides la extensión del texto.

4. Cuando hayas terminado de escribir tu texto, puedes entregarlo al profesor.

\section{NOTA IMPORTANTE:}

El texto que escribas será publicado en las carteleras informativas de esta Institución Educativa, para que todos los alumnos del grado 5ํㅡㄴ loan y puedan así escoger el mejor candidato. 
Lina María Moreno Serna - Angelmiro Galindo - Andrés Felipe Murillo

475 
La argumentación persuasiva en primaria desde la secuencia didáctica con enfoque metacognitivo

476 
Anexo B: Entrevista de reflexión del estudiante sobre el proceso de escritura y habilidades metacognitivas

Código

Entrevistador(es):

Entrevistado:

\section{Introducción}

La siguiente entrevista se realizará vía WhatsApp para conocer la percepción del estudiante sobre temas relacionados con el proceso de escritura. Esta entrevista cuenta con 10 preguntas las cuales buscan proveer información sobre las siguientes categorías:

- Autoevaluación y reflexión sobre los procesos comunicativos.

- Análisis y uso metapragmático de los mecanismos de persuasión.

- Proceso metacognitivo de escritura (planeación, textualización y revisión).

\section{Objetivo}

- Conocer las estrategias metacognitivas utilizadas por el estudiante en el proceso de escritura (planeación, textualización y revisión).

- Conocer la percepción del estudiante sobre la argumentación y el uso metapragmático de los mecanismos de persuasión.

- Conocer la percepción de los estudiantes sobre las guías implementadas

\section{Instrucciones}


El tiempo aproximado para cada entrevista será de 15 minutos. El entrevistador se encargará de explicar los objetivos de la entrevista al estudiante y de realizar las respectivas preguntas. Las respuestas serán grabadas para su posterior transcripción y análisis. El entrevistador podrá tomar apuntes sobre aspectos que considere relevantes y también podrá reestructurar las preguntas cuando lo considere necesario.

\section{Preguntas}

- Autoevaluación y reflexión sobre los procesos comunicativos

1- ¿Consideras que es importante aprender a argumentar?

2- ¿Consideras que aprender a escribir este tipo de textos electorales es importante? ¿Por qué?

3- ¿Has tenido dificultades con las instrucciones de las guías?

4- ¿Qué actividades te han gustado más y por qué?

5- ¿Qué actividad te gustaría hacer en las guías?

- Proceso metacognitivo de escritura (planeación, textualización y revisión)

6- ¿Cuándo tienes que escribir este tipo de textos, sigues algunos pasos?

7- ¿Durante el proceso de escritura has identificado dificultadas para escribir este tipo de textos?

8- Si has tenido dificultades, ¿Cómo las resuelves?

- Análisis y uso metapragmático de los mecanismos de persuasión

9- ¿Qué debemos tener en cuenta al momento de escribir un texto persuasivo electoral?

10- ¿Qué crees qué debemos tener en cuenta al momento de votar?

\section{Observaciones}


Lina María Moreno Serna - Angelmiro Galindo - Andrés Felipe Murillo

479 
Anexo C: Entrevista de reflexión del docente sobre estrategias de enseñanza metacognitivas y percepción de la escritura argumentativa persuasiva

Entrevistador(es):

Entrevistado:

\section{Introducción}

La siguiente entrevista se realizará a través del software de video chat Zoom para conocer la percepción del docente del curso en cuanto al desarrollo y alcance de la implementación en el proceso de enseñanza y aprendizaje del texto argumentativo persuasivo de carácter electoral. Esta entrevista cuenta con 10 preguntas las cuales buscan proveer con información al investigador sobre las siguientes categorías:

- Estrategias metacognitivas de enseñanza.

- Percepción de la argumentación persuasiva de carácter electoral.

- Autoevaluación y reflexión sobre los procesos comunicativos.

- Desempeño en la construcción de la estructura textual.

- Análisis y uso metapragmático de los mecanismos de persuasión.

- Proceso metacognitivo de escritura (planeación, textualización y revisión). 


\section{Objetivo}

Conocer la percepción del docente del curso en cuanto al desarrollo y alcance de la implementación en el proceso de enseñanza y aprendizaje del texto argumentativo persuasivo de carácter electoral.

\section{Instrucciones}

El tiempo aproximado para esta entrevista será de 45 minutos. El entrevistador se encargará de realizar la pregunta, la respuesta será grabada para su posterior transcripción y análisis. El entrevistador podrá tomar apuntes sobre aspectos que considere relevantes y también podrá reestructurar las preguntas cuando lo considere necesario. La entrevista se llevará a cabo mediante el software de video chat Zoom.

\section{Preguntas}

\section{- Estrategias metacognitivas de enseñanza}

1. ¿Qué estrategias de enseñanza se emplean para fomentar el aprendizaje guiado y consciente de la escritura de textos argumentativos?

2. Teniendo en cuenta las dificultades en la comprensión de las instrucciones detectadas, ¿qué aspectos de orden metodológico, procedimental o de contenido se deben tener en cuenta para mejorar el aprendizaje de la argumentación persuasiva de carácter electoral en los estudiantes?

3. ¿Qué tipo de actividades se deben desarrollar para mejorar el aprendizaje de la argumentación persuasiva de carácter electoral?

\section{- Percepción de la argumentación persuasiva electoral}

4. ¿Considera usted importante la formación en argumentación persuasiva de carácter electoral? ¿por qué? 
- Autoevaluación y reflexión sobre los procesos comunicativos

5. ¿En la formación académica de los estudiantes se tiene en cuenta este tipo de texto? Si/ no ¿por qué?

6. ¿Los estudiantes han presentado dificultades en la comprensión de las instrucciones y el contenido propuesto en las guías? Si este es el caso, ¿qué tipo de dificultades?

- Desempeño en la construcción de la estructura textual

7. ¿Los textos elaborados por los estudiantes corresponden a un texto argumentativo persuasivo de carácter electoral? Si no ¿por qué?

8. ¿Ha observado falencias o debilidades en el desempeño de los estudiantes en cuanto a la escritura del texto argumentativo persuasivo de carácter electoral? (uso de la estructura, estrategias del texto persuasivo o tipos de argumentos, puntuación, uso de conectores).

- Análisis y uso metapragmático de los mecanismos de persuasión

9. ¿En los ejercicios propuestos sobre texto argumentativo persuasivo electoral en la guía 4, ¿Qué hace el estudiante para lograr persuadir?

- Proceso metacognitivo de escritura (planeación, textualización y revisión).

10. ¿El estudiante sigue las instrucciones de orden metacognitivo durante el proceso de escritura (antes, durante y después) dadas en las guías? 
Lina María Moreno Serna - Angelmiro Galindo - Andrés Felipe Murillo

Observaciones

483 